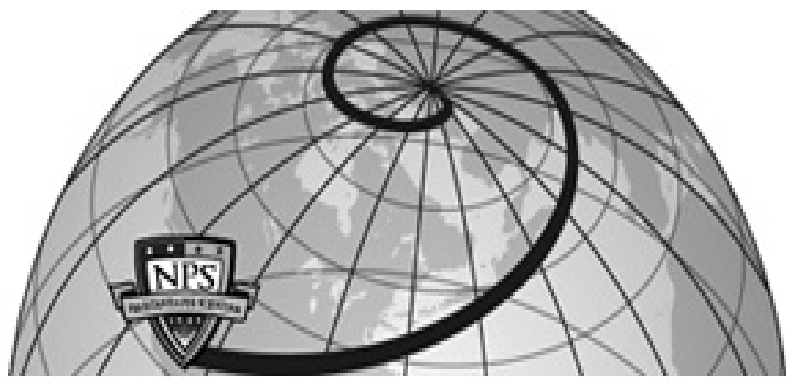

Calhoun: The NPS Institutional Archive DSpace Repository

1997-12

\title{
Environmental testing of the Petite Amateur Navy Satellite (PANSAT)
}

Overstreet, Paul J.

Monterey, California. Naval Postgraduate School

http://hdl.handle.net/10945/8312

This publication is a work of the U.S. Government as defined in Title 17, United States Code, Section 101. Copyright protection is not available for this work in the United States.

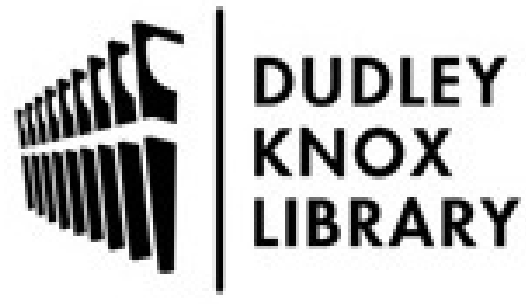

http://www.nps.edu/library
Calhoun is the Naval Postgraduate School's public access digital repository for research materials and institutional publications created by the NPS community. Calhoun is named for Professor of Mathematics Guy K. Calhoun, NPS's first appointed -- and published -- scholarly author.

Dudley Knox Library / Naval Postgraduate School 411 Dyer Road / 1 University Circle Monterey, California USA 93943 


\section{NPS ARCHIVE}

1997.12

OVERSTREET, $P$. 


\section{DUDLEY KNOX LIBRARY}

NAVAL POSTGRADUATE SCHOOL

MONTEREY CA 93943-5101 




\section{NAVAL POSTGRADUATE SCHOOL MONTEREY, CALIFORNIA}

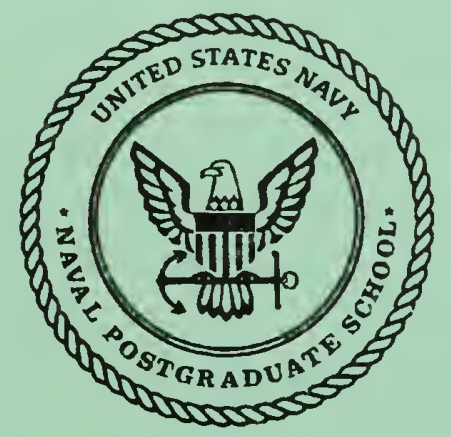

\section{THESIS}

ENVIRONMENTAL TESTING OF THE PETITE AMATEUR NAVY SATELLITE (PANSAT)

by

\section{Paul J. Overstreet}

December 1997

Thesis Advisor:

Dan Sakoda

Co-Advisor:

I. Michael Ross

Approved for public release; distribution is unlimited. 



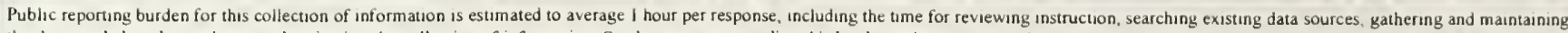

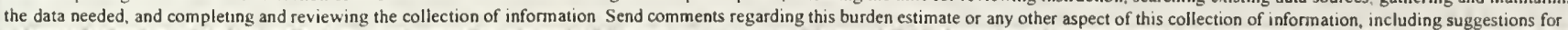

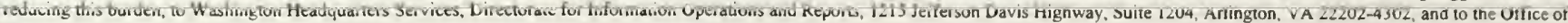
Management and Budget, Paperwork Reduction Project (0704-0188) Washington DC 20503

\begin{tabular}{||l|l|l|l}
\hline 1. AGENCY USE ONLY (Leave blank) & $2 . \quad \begin{array}{l}\text { REPORT DATE } \\
\text { December } 1997\end{array}$ & $\begin{array}{l}\text { R. } \\
\text { REPORT TYPE AND DATES COVERED } \\
\text { Master's Thesis }\end{array}$ \\
\hline
\end{tabular}

4. TITLE AND SUBTITLE

5. ENVIRONMENTAL TESTING OF THE PETITE AMATEUR NAVY SATELLITE (PANSAT)

6. AUTHOR(S) Paul J. Overstreet

7. PERFORMING ORGANIZATION NAME(S) AND ADDRESS(ES)

Naval Postgraduate School

Monterey CA 93943-5000

9. SPONSORING/MONITORING AGENCY NAME(S) AND ADDRESS(ES)

5. FUNDING NUMBERS

8. PERFORMING ORGANIZATION REPORT NUMBER

10. SPONSORING/MONITORING AGENCY REPORT NUMBER

11. SUPPLEMENTARY NOTES The views expressed in this thesis are those of the author and do not reflect the official policy or position of the Department of Defense or the U.S. Government.

12a. DISTRIBUTION/AVAILABILITY STATEMENT

Approved for public release; distribution is unlimited.

12b. DISTRIBUTION CODE

13. ABSTRACT (maxımum 200 words)

Any complex and expensive system requires testing to ensure adequate performance. Communications satellites require extensive testing for two additional reasons: they operate in an environment considerably different from that in which they were built and, after launch, they are inaccessible to routine maintenance and repair. The objectives of testing is not necessarily to duplicate the space environment but to approach it sufficiently so that any spacecraft that passes the tests will operate successfully in its designed space environment. The major features of the space environment that are difficult to simulate exactly are zero gravity, high vacuum, solar radiation, particle radiation and extreme temperatures. This document describes the environmental test program and test results for the PANSAT program. PANSAT is the acronym for the Petite Amateur Navy Satellite, which is a small communications satellite under development by the Space Systems Academic Group at the Naval Postgraduate School. PANSAT subsystems were subjected to thermal vacuum and random vibration testing as part of the overall environmental test program. Satellite launch, as a Shuttle secondary payload via the Space Transportation System ((STS) Small Self-contained Payload (SSCP) program, is planned for October, 1998.

\begin{tabular}{|c|c|c|c|c|c|c|c|}
\hline 14. & \multicolumn{5}{|c|}{ SUBJECT TERMS Environmental Testing, PANSAT, Spacecraft Testing. } & $\begin{array}{l}15 . \\
16 .\end{array}$ & NUMBER OF PAGES \\
\hline 17. & $\begin{array}{l}\text { SECURITY CLASSIFICATION } \\
\text { OF REPORT } \\
\text { Unclassified }\end{array}$ & & $\begin{array}{l}\text { SECURITY CLASSIFICATION } \\
\text { OF THIS PAGE } \\
\text { Unclassified }\end{array}$ & & $\begin{array}{l}\text { SECURITY CLASSIFICATION } \\
\text { OF ABSTRACT } \\
\text { Unclassified }\end{array}$ & 20. & $\begin{array}{l}\text { LIMITATION OF } \\
\text { ABSTRACT } \\
\text { UL }\end{array}$ \\
\hline
\end{tabular}



Approved for public release; distribution is unlimited.

ENVIRONMENTAL TESTING OF THE PETITE AMATEUR NAVY SATELLITE (PANSAT)

\author{
Paul J. Overstreet \\ Lieutenant Commander, United States Navy \\ B.S., United States Merchant Marine Academy, 1985
}

Submitted in partial fulfillment

of the requirements for the degree of

MASTER OF SCIENCE IN ASTRONAUTICAL ENGINEERING

from the

NAVAL POSTGRADUATE SCHOOL

Degember 1997 , , I 



\section{ABSTRACT}

Any complex and expensive system requires testing to ensure adequate performance. Communications satellites require extensive testing for two additional reasons: they operate in an environment considerably different from that in which they were built and, after launch, they are inaccessible to routine maintenance and repair. The objectives of testing is not necessarily to duplicate the space environment but to approach it sufficiently so that any spacecraft that passes the tests will operate successfully in its designed space environment. The major features of the space environment that are difficult to simulate exactly are zero gravity, high vacuum, solar radiation, particle radiation and extreme temperatures. This document describes the environmental test program and test results for the PANSAT program. PANSAT is the acronym for the Petite Amateur Navy Satellite, which is a small communications satellite under development by the Space Systems Academic Group at the Naval Postgraduate School. PANSAT subsystems were subjected to thermal vacuum and random vibration testing as part of the overall environmental test program. Satellite launch, as a Shuttle secondary payload via the Space Transportation System (STS) Small Self-contained Payload (SSCP) program, is planned for October, 1998. 


\section{TABLE OF CONTENTS}

I. INTRODUCTION

A. PANSAT OVERVIEW

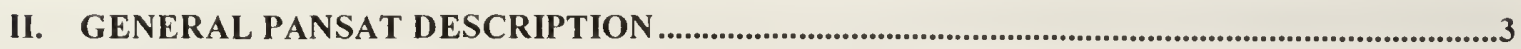

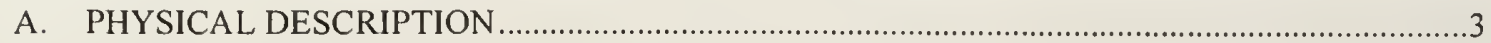

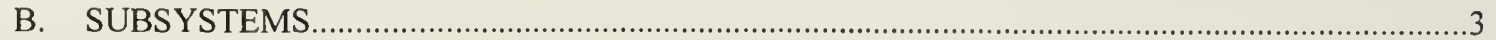

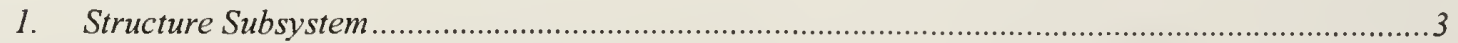

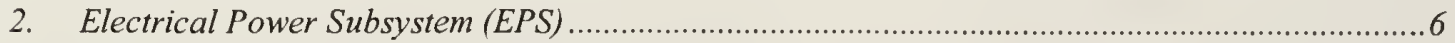

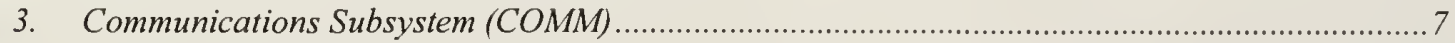

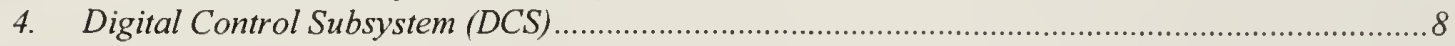

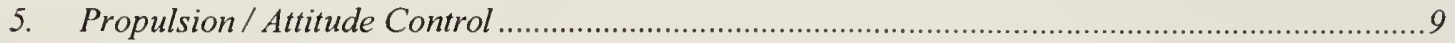

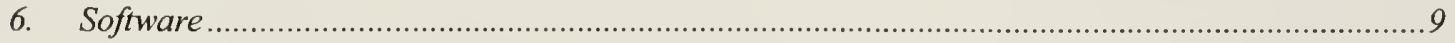

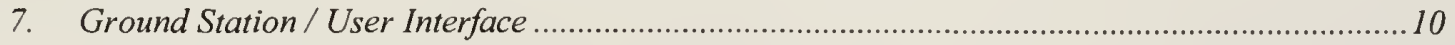

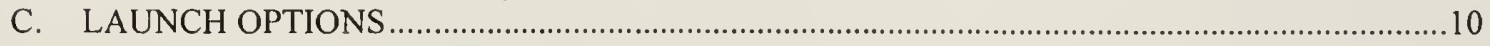

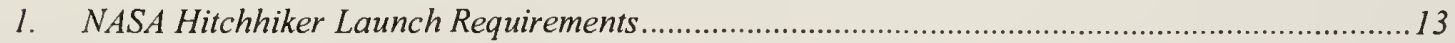

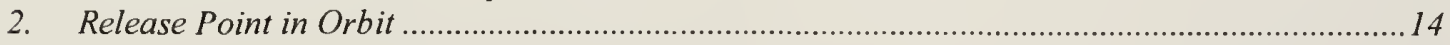

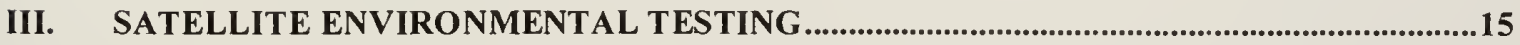

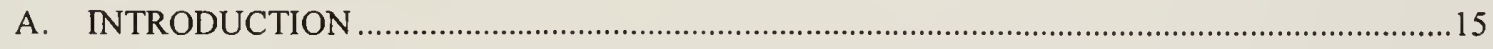

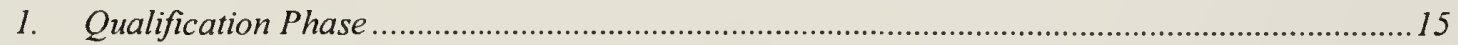

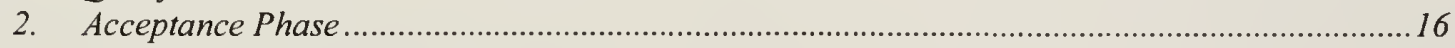

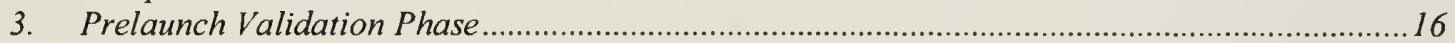

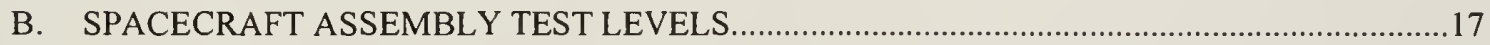

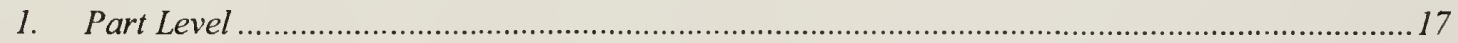

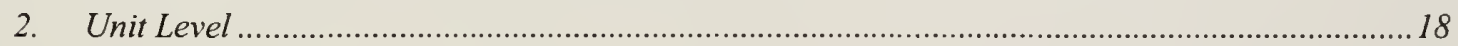

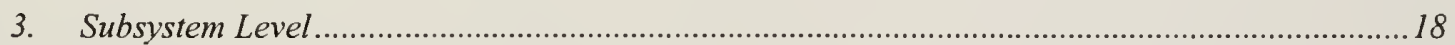

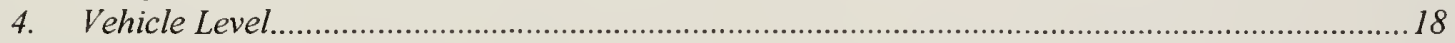

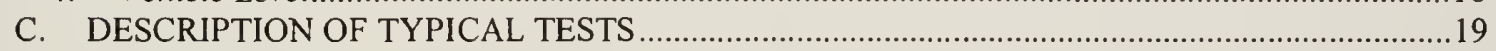

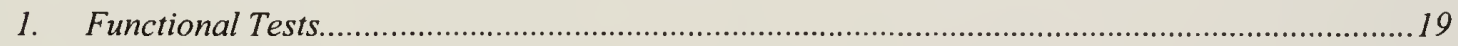

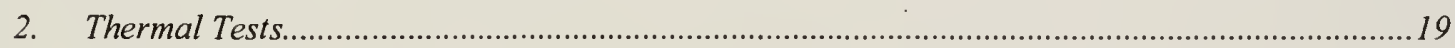

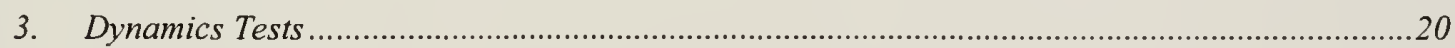

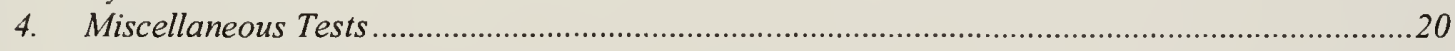

IV TESTING AND THE LAUNCH ENVIRONMENT.............................................................21

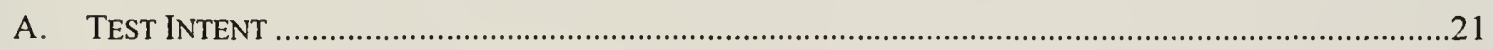

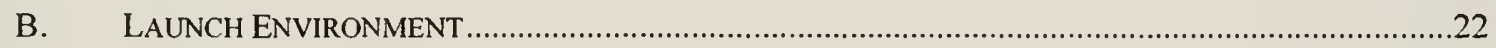

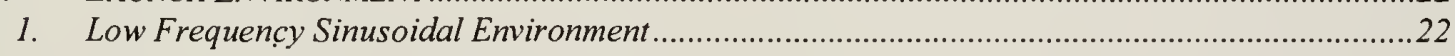

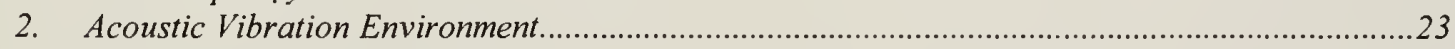

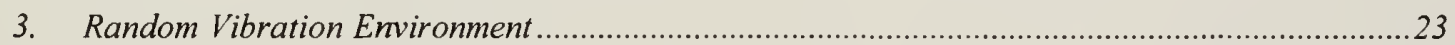

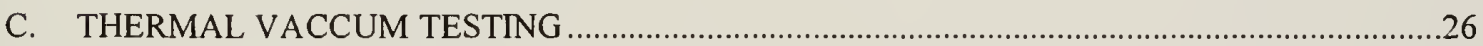

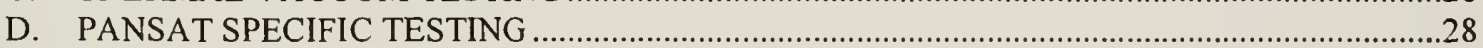

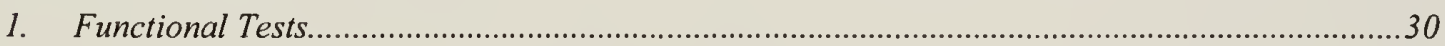

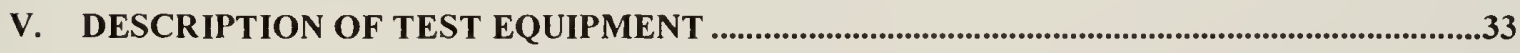

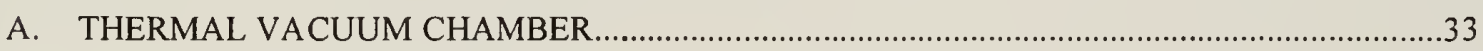

B RANDOM VIBRATION SHAKER

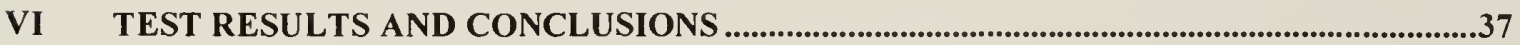

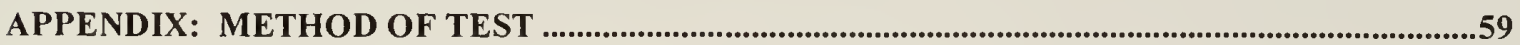




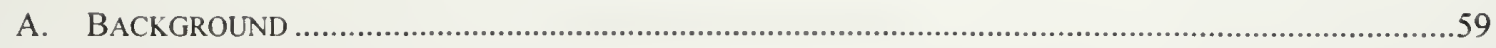

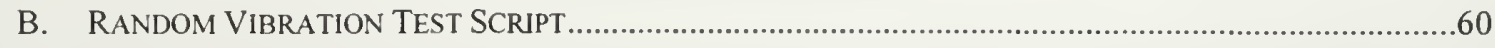

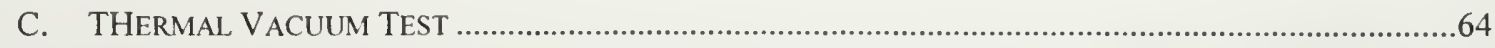

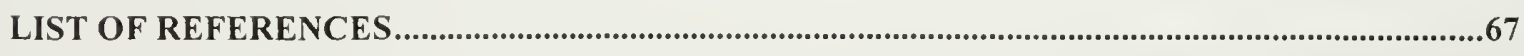

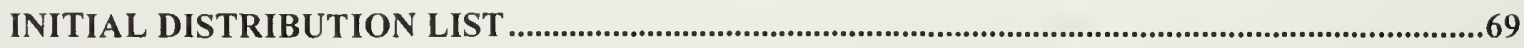




\section{ACKNOWLEDGMENT}

I would like to express my sincere appreciation to my thesis advisor, Dan Sakoda, as well as my co-advisor Prof. I. Michael Ross. Their guidance, encouragement, and advice during this endeavor were invaluable. I would also like to thank the other Space Systems Academic Group personnel with whom I've worked with: David Rigmaiden, Ron Phelps, and Jim Horning. Finally, I would like to thank my parents who taught me the value of an education, and my wife Lisa and daughter Kaley who give me all my inspiration. 



\section{INTRODUCTION}

\section{A. PANSAT OVERVIEW}

PANSAT is the acronym for the Petite Amateur Navy Satellite, which is a small communications satellite (see Figure 1.1) that has been under development since 1989 by the Space Systems Academic Group (SSAG) at the Naval Postgraduate School (NPS). The SSAG is an interdisciplinary association of academic departments at NPS that manages and fosters the space systems curricula and directs and sponsors space research. PANSAT provides opportunities for handson system design, hardware and software development, system integration, testing, and operational studies and exists primarily for the education of the officer students stationed at NPS. Satellite launch, as a Shuttle secondary payload via the Space Transportation System (STS) Small Self-contained Payload (SSCP) program, is tentatively planned for October, 1998 on STS-95. The actual launch date will be determined by PANSAT's completion date as well as by the STS schedule.

As part of the PANSAT test program, the system will undergo a complete set of environmental tests consisting of vibration and thermal vacuum cycling. These tests are done to verify that the satellite will operate properly in the extreme temperatures and low pressures experienced in space, and that it will survive the vibrations expected during the launch phase. 


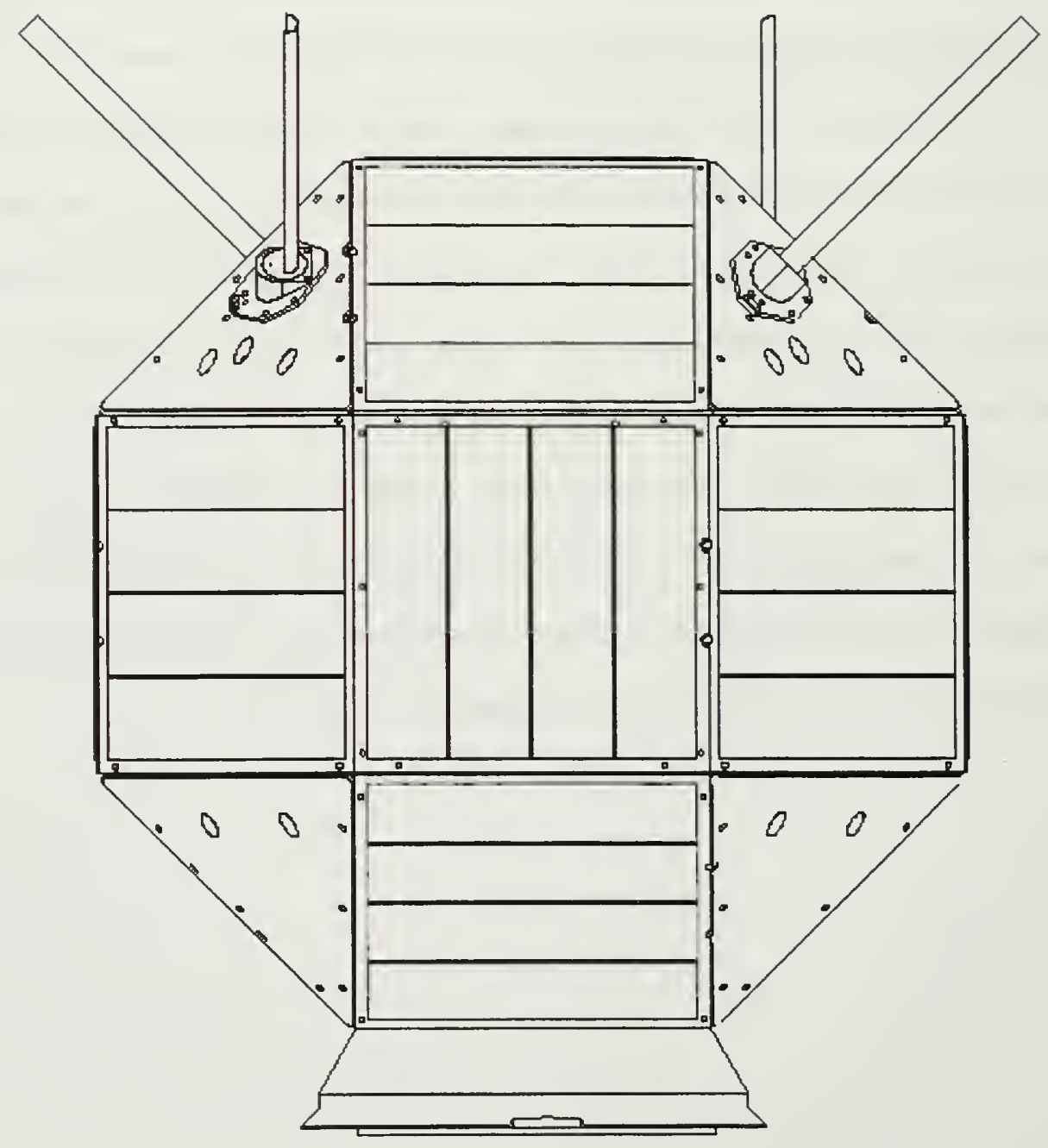

Figure 1.1 PANSAT (Courtesy of Dan Sakoda) 


\section{GENERAL PANSAT DESCRIPTION}

\section{A. PHYSICAL DESCRIPTION}

PANSAT's 26-sided, polyhedral shaped exterior is composed of 18 solar panels, a base-plate, or Launch Vehicle Interface (LVI) for attachment to the launch vehicle, four dipole antennas mounted on four triangular-shaped surfaces, and four additional triangular-shaped surfaces. The eight triangular surfaces will be coated for passive thermal control. Since PANSAT will tumble along its flight path, this configuration provides an uneven distribution of solar energy on the solar arrays. The spacecraft will weigh less than $150 \mathrm{lbs}$. and will be 18.62 inches in diameter and 19.5 inches in height, which will provide the necessary internal space for the assorted subsystems while keeping it within the strict payload envelope imposed by the STS SSCP program. [Ref 1]

\section{B. SUBSYSTEMS}

\section{Structure Subsystem}

PANSAT is approximately spherical in shape and incorporates modularity for ease of fabrication and component installation. The .0625 in. thick frame panels provide stiffness for the structure and a 7.125 in. $\times 7.125$ in. surface for mounting the solar arrays. The entire structure employs aluminum (6061-T6), which features a high strength-to-weight ratio as well as good machining properties.

The LVI, attaches the satellite structure to the ejection mechanism of the Get Away Special (GAS) canister. The adapter meets two distinct design requirements: [Ref. 2] '

- the design must be robust enough to survive worst case scenarios, i.e., worst case launch loading at maximum satellite mass during shuttle launch, during the ejection sequence from the GAS canister, and during possible landing in the shuttle in the event of a mission abort, and 
- the design must be of sufficient stiffness so as to not allow the frequency of the LVI to couple with the natural frequency of the shuttle.

The internal satellite structure is composed of upper and lower equipment platforms, two end blocks, and a cylindrical shell, and is depicted in Figure 2.1. The 0.0625 in. thick cylinder is mounted directly to and supports the lower equipment plate. As the main load-bearing structure, the cylinder transfers loads from the spacecraft to the LVI. The lower equipment plate is .30 in. thick and is designed to carry up to $85 \mathrm{lbs}$. of equipment, which represents $57 \%$ of total allowable spacecraft weight, while the upper equipment plate is in excess of .25 in. thick and is capable of supporting in excess of $37.5 \mathrm{lbs}$. of equipment. The equipment plates are thicker than structurally needed but this eases the fastening of subsystems as well as aids the satellite in the attainment of the targeted weight. The discrepancies between upper and lower equipment plate thickness and load bearing capacities are due to the added stiffness that the support cylinder provides to the lower plate. An aluminum mock-up of the entire structure was built to physically demonstrate allowable subsystem envelopes and to provide a model for vibration testing. [Ref. 3] 


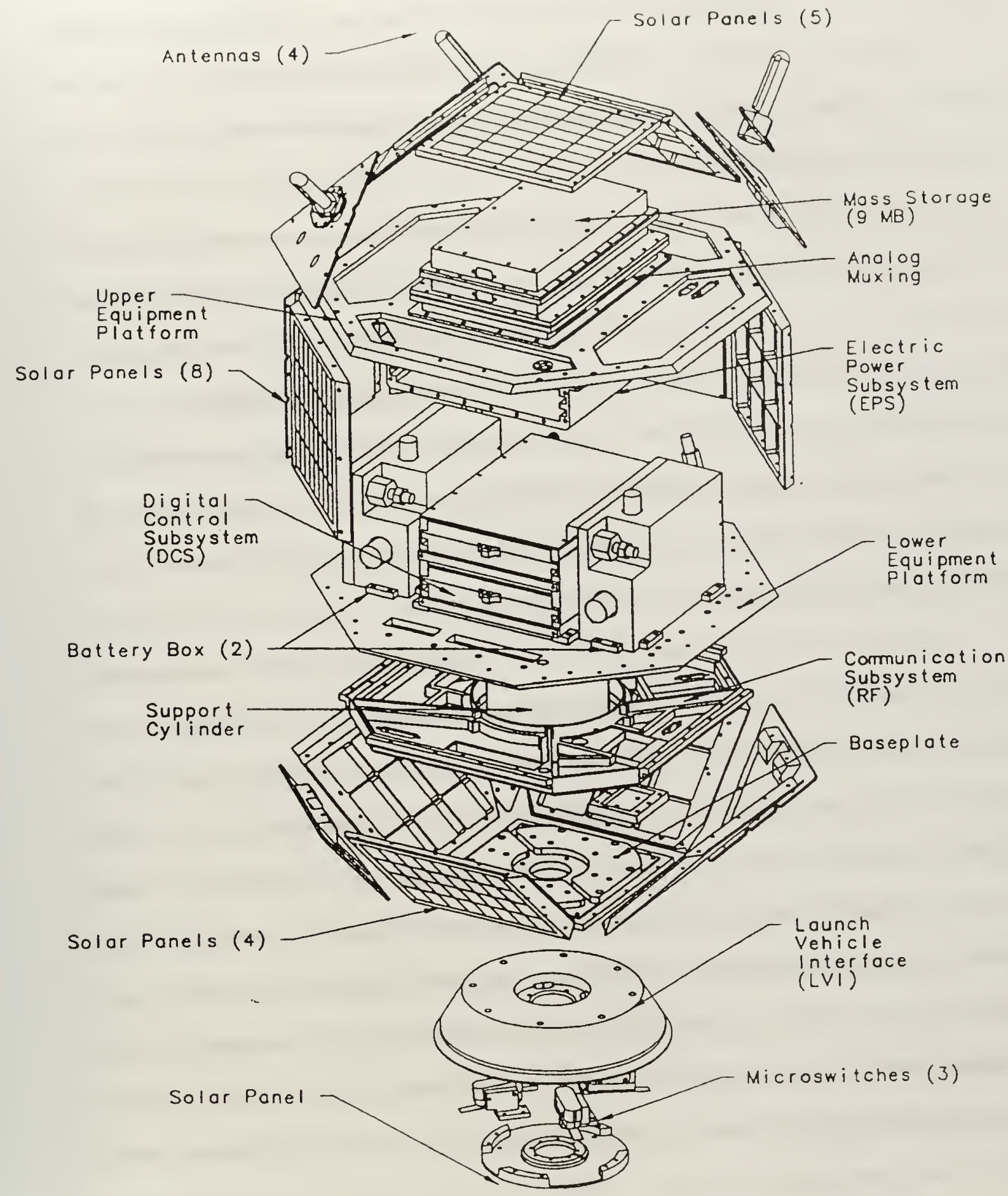

Figure 2.1 PANSAT Internal Configuration (Courtesy of Dan Sakoda) 


\section{Electrical Power Subsystem (EPS)}

The Electrical Power Subsystem (EPS), which is designed to provide efficient power distribution to all satellite subsystems, consists of three major components: 18 solar panels for primary power conversion (17 silicon and one gallium arsenide), two nickel-cadmium (NiCd) batteries for power during eclipse, and power regulation/conditioning and telemetry circuitry, current sensing circuits and voltage multiplexing circuitry.

The EPS relies on the main spacecraft processor for the activation of relays and for the determination of battery charge levels and charge cycles. Power will be distributed via an unregulated power bus, at $12 \mathrm{~V} \pm 3 \mathrm{~V}$, to the Digital Control Subsystem (DCS) and to the Communication Subsystem (COMM). Ideally, PANSAT ejection will occur immediately after the Shuttle emerges from the eclipse portion of its orbit. In this manner, the spacecraft would be subjected to sunlight for the maximum amount of time at beginning-of-life (BOL), allowing battery charging. When the spacecraft enters eclipse during the early stages of the mission, a low-power mode of operation will be enabled until one of the batteries reaches sufficient capacity. [Ref. 4]

The purpose of PANSAT's silicon solar panels is to provide power to the electrical bus during periods of sunlight and to charge the batteries. Silicon cells were chosen due to their low cost and adequate power efficiency. A minimum efficiency of $14.5 \%$ at Air Mass Zero (AMO) and $28^{\circ} \mathrm{C}$ was deemed necessary based on the initial power budget estimates. Each silicon cell is $1.92 \mathrm{~cm} \mathrm{x} 4.00 \mathrm{~cm}$. Each of the 17 silicon solar panels consists of 32 series-connected cells, redundantly wired. Each solar panel encompasses an area of approximately 256 square centimeters. The solar panels were fabricated by Spectrolab, Inc. of Sylmar, California, and utilize the K6700A silicon cell with backsurface field and back-surface reflector (BSFR). A Gallium Arsenide (GaAs) solar panel is used on the bottom, external surface of the LVI was built by Satellite Power Corporation. The LVI panel provides a smaller area available than the other 17 body panels and utilizes GaAs cells due to their greater efficiency and higher voltage output. All solar panels will have their outputs clamped at, or limited to, 16 volts. The two NiCd batteries are responsible for providing power when PANSAT is in eclipse. Optimally, the batteries will be capable of maintaining bus voltage at 12 volts. Additionally, 
during eclipse operations, the NiCd batteries are tasked with voltage regulation. Voltage sensors monitor the solar panel voltages and battery voltages, while thermal sensors keep track of solar panel, battery, and electronics housing temperatures. [Ref. 5]

\section{Communications Subsystem (COMM)}

The COMM subsystem is simplex, or half-duplex, which means it incorporates a single channel for both up-link and down-link, with the up-link and down-link functions being mutually exclusive (i.e., they do not occur at the same time). Data rate will be 9.842 kilobits per second (kbps). The spacecraft will operate at a center frequency of $436.5 \mathrm{MHz}$ in the amateur radio $70-\mathrm{cm}$ band and will occupy a bandwidth of $2.5 \mathrm{MHz}$.

In compliance with the federal regulations, the pseudo-noise (PN) code sequence is implemented by using a 7-bit shift register with taps at 7 and 1 . The PN code is combined with the data stream at a rate of 1 sequence length per bit of information. The spread signal is then modulated using binary-phase-shift-keying (BPSK) and up-converted to the transmitted carrier. The transmitter aboard PANSAT is capable of varying the output power so as to use only the minimum amount required for successful reception. [Ref. 4]

The spread spectrum receiver onboard PANSAT provides signal detection, tracking, and demodulation for recovery of the digital data stream. The data stream is passed to a serial communication controller (SCC) for de-packetizing and error-checking by means of a cyclical redundancy check (CRC). The recovered data is then delivered to the spacecraft DCS for processing. The receiver is capable of receiving a carrier of at least $-120 \mathrm{dBm}$ signal strength. [Ref. 4]

The COMM system has been developed around a digital design that became available through Application Specific Integrated Circuit (ASIC) technology, the PARAMAX PA-100. The PA-100 provides for much of the functionality of spread spectrum, on just a single chip, which replaces several full circuit boards of analog components. The chip incorporates the following features: [Ref. 5]

- De-spreading, demodulation, Costas Loop carrier recovery, PN code detection and tracking, data synchronization, and Automatic Gain Control (AGC) all on one chip. 
- Data rate up to 64 Megabits per second (Mbps) (PANSAT rate remains $9.842 \mathrm{kbps}$ ).

- Chipping rate up to $32 \mathrm{Mcps}$ (PANSAT rate is $1.25 \mathrm{MHz}$ ).

- Multiple modulation modes including Binary Phase Shift Keying (BPSK) and Quadrature Phase Shift Keying (QPSK).

- Spread or clear communications modes.

- Maximum $48 \mathrm{~dB}$ processing gain.

- Low bit error rate.

- Simple 8-bit controller interface with the DCS.

The PA-100 consists of Direct Sequence Spread Spectrum (DSSS) transmitters and receivers with some level of redundancy, although there are still some single-points of failure present in the system. Each transmitter and receiver is capable of switching from wide-band spread spectrum modulation to narrow-band BPSK modulation, which allows for emergency operation and the downlinking of a narrow band telemetry beacon. BPSK is important for users who are in the early stages of setting up their ground stations and/or for users whose equipment is not spread spectrum capable. [Ref. 4]

To facilitate two-way communications, four antennas will be attached to four of the triangular surface panels on the exterior of the structure. The four dipole antennas will be placed in a tangential turnstile configuration and will provide omni-directional coverage. Radiated power from the antennas will be five watts or less. [Ref. 6]

\section{Digital Control Subsystem (DCS)}

The primary functions of the Digital Control Subsystem (DCS) is to :

- provide control and monitoring of the EPS,

- provide control and operation of the COMM payload, gather, organize, and store telemetry data,

- perform management of onboard non-volatile memory, and

- $\quad$ provide control of message traffic. [Ref. 4] 
The DCS design implements both a multi-tasking operating system to provide store-and-forward communications and "pair and spare" technology to provide redundancy for space operations. The DCS design consists of dual, mutually exclusive control boards to provide the desired redundancy, each run by an Intel M8OCl86XL microprocessor. The M8OC186XL microprocessor was selected because of its proven architecture, radiation tolerance, low power consumption, availability of development tools, and capability of supporting a multi-tasking environment. The DCS control boards communicate with redundant four-megabyte mass storage units and temperature multiplexing (TMUX) modules for temperature.

\section{Propulsion / Attitude Control}

PANSAT possesses no propulsion subsystem and is designed to "tumble" along its orbital path once it is released from the launch vehicle. The satellite orbit will be determined by the launch vehicle at ejection and the satellite will not be capable of any orbital maneuvers. Thus, the release point in orbit takes on added importance and will play a large part in the usable service life of the satellite.

\section{Software}

Software is an important aspect of the PANSAT program, encompassing three major design goals:

- maximum use of existing software with reliable functionality,

- requirement that software modifications, as well as new software modules, can be uploaded to and exercised on PANSAT subsequent to launch, and

- compatibility of software developed at NPS with Amateur Radio software and standards presently in use.

In order to maintain adherence to strict timing requirements, certain low-level functions will be coded in 80186 assembly language. Intel's ApBuilder, which is a software development tool for microprocessor initialization and configuration set-up, was used to assist in the generation of initialization code for each peripheral embedded. However, $\mathrm{C}$ was used to implement the majority of 
the software because of the familiarity of team members with the language, the availability of tools, and the ease of integration with other third party software operating systems. [Ref 7]

\section{Ground Station / User Interface}

After initialization, PANSAT will conduct normal operations by remaining in a receive-only mode at all times, waiting for a request-to-connect command from the ground station. After acknowledging the user, PANSAT will begin the information-relay phase, during which the user will be able to access a bulletin board service. The bulletin board offers services that allow the user to send and receive mail that is stored on-board PANSAT, upload and download files, and read spacecraft telemetry. The use of sophisticated protocols will allow users to interleave their activities with those of PANSAT, thereby enabling multiple users to communicate simultaneously with the satellite. When the information-relay is complete, the user will $\log$ out and the station will send a request-todisconnect command to end the session. [Ref. 7]

Users should be able to access PANSAT by using a personal computer, a Terminal Node Controller (TNC), radio transmission and receiving equipment, special spread spectrum hardware and PANSAT-specific user-interface software. The SSAG is developing a design for an inexpensive, generic Ham kit to provide an amateur radio operator with all of the necessary hardware and software required for the demodulation of the spread spectrum signal and communication with PANSAT. [Ref. 8]

\section{LAUNCH OPTIONS}

In principle, PANSAT is suitable for launch by a variety of platforms, including the Space Shuttle, Pegasus, Scout, Delta series, Titan series, Atlas series, and Taurus. The Space Shuttle was selected as the launch vehicle because NASA launches the Space Shuttle on a frequent basis, thereby providing numerous opportunities for manifest as a secondary payloads. Prior to launch on the Space Shuttle, PANSAT will be transported from Monterey, California, to the Goddard Space Flight Center 
(GSFC), where it will undergo integration with the Hitchhiker canister. The canister, with PANSAT inside, will then be transported to Cape Canaveral, Florida, for final integration.

PANSAT will fly on the Space Shuttle as a Small Self-Contained Payload (SSCP), which utilizes the Hitchhiker $(\mathrm{HH})$ program. The $\mathrm{HH}$ payloads are loaded into $\mathrm{HH}$ canisters, which are located in the cargo bay of the Shuttle. PANSAT will require a HH canister without a door assembly but with a launch mechanism, and will fly as a free-flier experiment. The modified $\mathrm{HH}$ canister is shown in Figure 2.2. The NASA standard ejection mechanism for $\mathrm{HH}$ launches consists of a pedestal, a spring-loaded plunger, a 9-in.-diameter Marman Clamp retention system, and two pyrotechnic guillotine cutters that sever two bolts and release the Marman clamp. When released, the spring pushes the payload out of the canister at approximately 3.5 feet per second. 


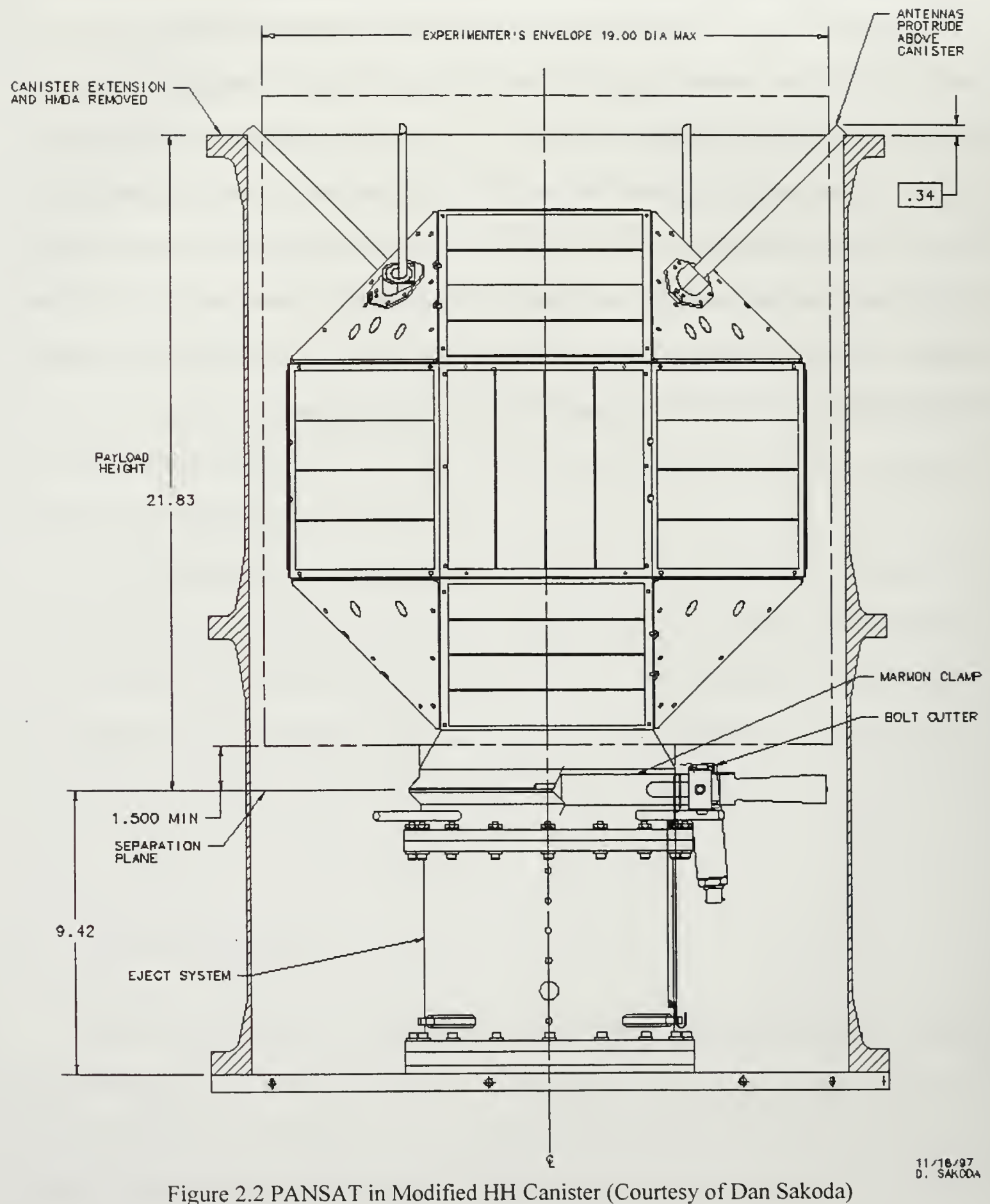


PANSAT will be in a dormant state inside of the HH canister while attached to the Space Shuttle. The canister provides the requisite thermal protection for the payload by utilizing heaters/thermostat control as well as heat removal by radiation.

\section{NASA Hitchhiker Launch Requirements}

In 1984, the NASA headquarters office of space flight established "Hitchhiker"

Projects at the Goddard Space Flight Center (GSFC) and Marshall Space Flight Center (MSFC) to develop and operate carrier systems for low-cost and quick-reaction accommodation of secondary payloads on the NASA Space Shuttles. The Hitchhiker carriers can carry payloads side mounted in the Shuttle payload bay or mounted on a cross-bay "bridge" structure. Both carriers have the same electrical systems and provide the same electrical interfaces and services for payload related equipment. Either carrier can accommodate equipment mounted in a standard canister or on a standard vertical mounting plate.

NASA requires that all customer equipment be designed to withstand the launch, operational, reentry, and landing environments of the Shuttle without failures, leaking hazardous fluids, or releasing equipment and loose debris particles that could damage the Space Shuttle or cause injury to the crew. All flight equipment must be tested in order to qualify it for the Shuttle vibroacoustic environment. Figure 2.3 is the vibration specification for Shuttle equipment to which PANSAT is being tested. 


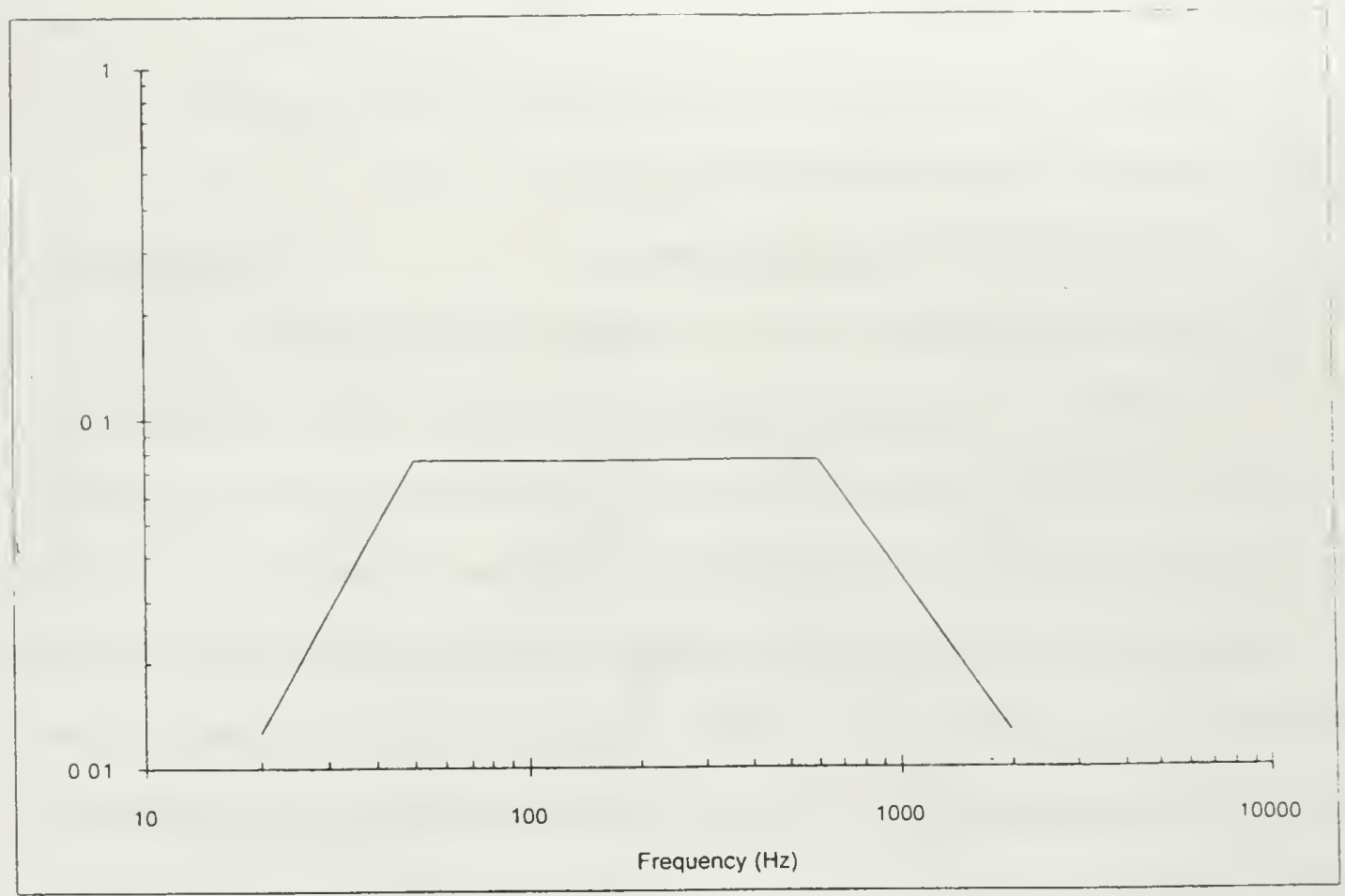

Figure 2.3 NASA Vibration Test Level Requirement

\section{Release Point in Orbit}

PANSAT is a secondary payload and accordingly will have to accept whatever orbital elements that the primary payload demands. The requested, but not guaranteed, orbit insertion point would occur in the first five minutes of the sunlit portion of the orbit. PANSAT would then be ejected with its separation velocity vector coaligned with the sun vector. The altitude and inclination for the scheduled STS-95 mission is at $310 \mathrm{NM}(574.1 \mathrm{~km})$ for altitude and $28.45^{\circ}$ for inclination. 
III. SATELLITE ENVIRONMENTAL TESTING

\section{A. INTRODUCTION}

Any complex and expensive system requires testing to ensure adequate performance. Communications satellites require extensive testing for two additional reasons: they operate in an environment considerably different from that in which they were built and, after launch, they are inaccessible to routine maintenance and repair. The objective of testing is not necessarily to duplicate the space environment but to approach it sufficiently so that any spacecraft that passes the tests will operate successfully.

The major features of the space environment that are difficult to simulate exactly are zero gravity, high vacuum, solar radiation, particle radiation, and a full design lifetime. Except for zero gravity, approximate simulation of these parameters is possible for most spacecraft components. Gravity affects the deployment of solar arrays and antennas, and liquid motion in components such as fuel tanks, heat pipes, and batteries.

This document describes the satellite test program for subsystem, and spacecraft qualification, acceptance, and prelaunch spacecraft validation tests. The overall test program approach is to perform comprehensive testing of qualification and protoflight hardware as early as possible to ensure early identification and resolution of design, component, or fabrication problems. Any test program should: 1) qualify new or modified designs at the presystem and/or system level, 2) complete acceptance test all spacecraft units before installation on the spacecraft, and 3) conduct system level performance and environmental tests to verify specification compliance at the highest level possible.

The PANSAT spacecraft design will be qualified by the performance of tests which extend beyond their expected operating limits. Successful completion of qualification testing will provide sufficient margin to ensure satisfactory performance in the nominal operating environment.

\section{Qualification Phase}

Once the developmental testing has been accomplished to verify design concepts and reduce the risk of new technologies, efforts enter a flight qualification phase. During this phase, the 
qualification vehicle, which is as close to flight quality as possible, will be subjected to both functional and environmental tests to ensure that the design, materials, and manufacturing processes used in production meets mission specification requirements. The tests certify that both hardware and software work properly and that the hardware can survive and operate in the expected environment.

To ensure adequate design margins, the qualification vehicle is generally exposed to test levels higher than those expected in flight. Consequently, a spacecraft subjected to qualification testing is generally not intended to be flown and is often utilized as a permanent test fixture. However, to shorten the development cycle and reduce costs, a protoflight approach is sometimes taken. In this case the environmental test levels are lower than those used for the traditional qualification and the qualification article is actually used for flight. In using this approach, refurbishment of the test item may be necessary prior to flight.

\section{Acceptance Phase}

Once a spacecraft or component is qualified, other articles produced using the same design, materials and manufacturing process should also meet the design specifications and are therefore considered qualified for flight without being subject to qualification tests. However, because materials, and manufacturing processes are imperfect, some testing is required to demonstrate conformance to specification requirements and provide quality control assurance against workmanship or material deficiencies. Consequently, the vehicles or components produced after the qualification are subjected to acceptance tests to demonstrate that the hardware is ready for flight. These acceptance tests are designed to stress items to find failures due to latent defects in parts, materials and workmanship using test levels which are generally not as severe as those used for qualification.

\section{Prelaunch Validation Phase}

During the prelaunch validation phase, additional testing will be accomplished to ensure spacecraft readiness for launch. Such testing will be conducted both before and after shipping to the launch site and is unique for each program depending on transportation methods and the launch vehicle integration process. 
Prelaunch operations will include functional testing, pressurization and checkout, ordnance system verification, launch vehicle mechanical and electrical integration and verification, prelaunch countdown simulations and battery charging. Following the successful completion of prelaunch validation activities, the spacecraft will be launched and on orbit checkout and operations will begin.

\section{B. SPACECRAFT ASSEMBLY TEST LEVELS}

The spacecraft development and testing process described above is executed at a variety of levels. Development, qualification and acceptance tests are not only conducted on the entire spacecraft after integration of all components, but each of the components and subsystems which make up the spacecraft are also subjected to tests on an individual basis prior to installation on the vehicle. As the test article becomes larger and more complex, the testing process becomes more costly and difficult to perform and failures are often much more difficult to repair. Consequently, the testing process is often tailored such that testing at a "lower" unit and component levels is more comprehensive and severe than testing at the "higher" system level. This approach is intended to detect and repair failures at the lower levels so that testing at higher levels can be reduced. Because the type and quality of testing done at lower levels can have a significant impact on the effectiveness of tests conducted at the system level, it is important to conduct proper testing at all levels.

\section{Part Level}

In actuality, spacecraft testing begins at the part level, where individual parts such as integrated circuits are screened to ensure they are manufactured properly and can withstand the space environment. If parts quality is low, tests at subsequent levels can have an abnormally high failure rate. For DoD space programs, parts are generally required to conform to MIL-STD-1546B, "Parts, Materials, and Processes Control Program for Space and Launch Vehicles," [Ref. 9], or MIL-STD1547B, "Electronic Parts, Materials, and Processes for Space and Launch Vehicles." [Ref. 10]. 


\section{Unit Level}

The unit level includes components such as electronics boxes, actuators, drive motors and batteries which are viewed as a complete and separate entity for the purposes of manufacturing, maintenance, or record keeping. Unit level testing is conducted during the developmental, qualification and acceptance phases of unit development and includes both functional and environmental tests such as vibration and thermal vacuum. Following the successful completion of these tests, a unit is integrated either with a subsystem or directly with the space vehicle for further tests. The type and quality of testing conducted at the unit level can have a significant impact on test results at the subsystem and system level. DoD spacecraft developmental programs generally conform to the requirements listed in MIL-STD-1540C [Ref. 11] for testing at the unit level.

\section{Subsystem Level}

According to MIL-STD-1540C, "a subsystem is an assembly of functionally related units which may include interconnection items such as cables or tubing, and the supporting structure to which they are mounted." While many units are integrated directly with the vehicle and are tested together for the first time at the system level, some units are first integrated and tested together at the subsystem level. Often subsystems which have speciạl test requirements and which can be tested apart from the entire spacecraft are tested in this manner.

\section{Vehicle Level}

Following the assembly of the spacecraft and integration of all units and subsystems, a series of tests are generally conducted at the vehicle, or system level. These tests include both functional and environmental tests and are intended to ensure that the entire vehicle meets either qualification or acceptance requirements as appropriate for the phase of development. Because many components of the spacecraft are integrated for the first time at the vehicle level, this testing is critical in the detection of problems with such items as wire harnesses, connectors and plumbing which cannot be completely tested at lower levels. In addition, while a high percentage of manufacturing and materials defects are 
detected at the unit and subsystem level, it has been shown that system level testing still exposes a significant number of unit level defects. [Ref. 12]

\section{DESCRIPTION OF TYPICAL TESTS}

A variety of different tests are performed on a spacecraft and its components during the different phases of development. Depending on program requirements, these tests may be performed at the unit, subsystem or vehicle levels, and often may be repeated at all three levels. These tests include functional tests, thermal and dynamics environment tests, and miscellaneous tests.

\section{Functional Tests}

Functional tests are intended to verify the mechanical and electrical performance of components at the unit, subsystem and vehicle level. Functional tests are generally performed at ambient temperature and pressure conditions prior to environmental tests to establish a performance baseline. After the test article has been subjected to the required environments, additional functional tests are conducted to determine the impact of the environments on the test article. Functional tests are sometimes executed while a test article is being subjected to an environment, but depending on the environment, this can be complicated and expensive, especially at the vehicle level.

\section{Thermal Tests}

Thermal environment tests typically include thermal cycling at the unit level, thermal vacuum tests at the unit and vehicle level and thermal balance testing at the vehicle level. Thermal cycling and thermal vacuum tests are intended to verify performance of the test article in the expected temperature and vacuum environments as well as to stress components to detect workmanship and materials deficiencies. Thermal balance testing, on the other hand, is performed to verify that the spacecraft thermal control system is able to maintain the vehicle and its components within the required operating temperature ranges when subjected to the thermal environment of space and to validate the thermal model. 


\section{Dynamics Tests}

Dynamics tests can include modal surveys, pyrotechnic shock, random vibration, acoustics and sinusoidal vibration testing. Various combinations of these tests can be performed at the unit, subsystem and system levels depending on the particular test program. Dynamics tests are conducted during the development and qualification phases to verify that the spacecraft structure and components can survive the expected dynamic environment, which is mostly a result of the launch process. Dynamics tests are also conducted during the acceptance phase to stress components to detect workmanship and materials deficiencies. Acoustic vibration tests have the advantage of good simulation for larger spacecraft with complex shapes and adequate excitation provided to the subsystems on the spacecraft exterior. Its disadvantages are that it is expensive, unable to excite subsystems near the mounting surfaces, and unable to provide enough force in the lower frequency region

\section{Miscellaneous Tests}

Additional tests which do not fit into the above categories include inspection, safe procedures reliability tests, margin validation pressure and leakage tests and electromagnetic compatibility (EMC) tests. These tests can be conducted throughout the various phases of spacecraft development and at the various levels of assembly. 


\section{A. TEST INTENT}

Dynamics testing of a spacecraft at the vehicle level is conducted for two primary purposes. The first purpose is that of qualification: to ensure that the hardware can survive and operate in the expected environment. For dynamics testing, this environment consists primarily of launch vehicle induced loads as well as pyroshock from the deployment of mechanisms in flight. Other contributors include ground transporation and handling, but these environments are typically less severe and will not be discussed further.

Dynamics testing is only one part of the overall process employed to ensure the space vehicle can withstand the dynamic environment. Another important part of the process is the development of an analytical model of the vehicle structure. This analytical model is used to conduct a simulation to verify that the spacecraft design is adequate to survive the expected dynamic loading. However, even when such a model is developed, testing needs to be performed to verify the accuracy of the model. In addition, testing is also performed to ensure the design can withstand environments which the analysis cannot accurately simulate.

The second purpose of dynamics testing is that of acceptance: to provide quality control assurance against workmanship or material deficiencies. These workmanship or material deficiencies are only problems if they result in the failure of the spacecraft to properly operate in the operational environment. Consequently, for the exposure of material and workmanship problems, the launch environment is again an important factor. Dynamics testing under launch conditions can expose material and workmanship defects that might not be detected in a static condition but which could occur in flight. [Ref. 11] 


\section{B. LAUNCH ENVIRONMENT}

The launch loads environment is made up of a combination of steady-state, low frequency transient, higher-frequency vibroacoustic and very high frequency shock loads. The overall limit loads can be obtained by combining the root-sum-square (RSS) of the low and high-frequency dynamic components with the steady state component. This results in the specification of the launch limit loads typically published for particular launch vehicles. In addition to the limit load specification, separate specifications for the low frequency transient and vibroacoustic environments are usually provided.

\section{Low Frequency Sinusoidal Environment}

The primary structural loads experienced by a spacecraft during launch usually occur as a result of quasi-static loads due to acceleration or low frequency launch vehicle bending modes. Launch vehicle modes of vibration which cause significant primary structural loads are generally very low frequency loads, less than $20 \mathrm{~Hz}$. Unless the spacecraft has resonant modes in this frequency range, little dynamic coupling may be expected and the launch loads may be considered as static loads criteria. [Ref. 13] These static loads are usually specified in terms of $g$ limits in the thrust and lateral axis. For some launch vehicles, specific events such as Main Engine Cutoff (MECO) can result in significant low frequency oscillations at the launch vehicle payload/interface. In these cases, the low frequency environment is specified in addition to the static loads criteria. Often referred to as the sinusoidal environment, this loading is typically expressed in terms of acceleration amplitude in g over frequency range of interest, which is usually under $200 \mathrm{~Hz}$.

In addition to specific events such as MECO, low frequency oscillations can be caused by certain launch vehicle phenomena such as POGO and chugging. POGO is a self excited longitudinal vibration which is generated through the closed loop interaction of the launch vehicle structure and propulsion system with combustion chamber pressure and thrust fluctuations. POGO is an initially divergent longitudinal vibration which will be stabilized and damped after 10 to 40 cycles. Typical POGO frequencies are 10 to $20 \mathrm{~Hz}$ for booster stages, resulting in $+/-1$ to $2 \mathrm{~g}$ output vibration levels at the payload. [Ref. 14] During the thrust build up and decay of liquid rocket engines, periodic thrust 
fluctuations may occur as a result of burning instabilities. Known as chugging, these fluctuations can result in vibration in the range of 60 to $90 \mathrm{~Hz}$ for approximately 10 cycles.

\section{Acoustic Vibration Environment}

The principal sources of the acoustic environment include the interaction of rocket motor exhaust with the surrounding air. This acoustic vibration is a function of rocket thrust, mass flow rate and geometry and generally decays to a negligible level shortly after launch. The second source of acoustic vibration is aerodynamic noise, which is a function of dynamic pressure, Mach number and vehicle geometry and is usually greatest in the region of maximum aerodynamic pressure, or max $\mathrm{Q}$. Consequently, the two periods of concern with regard to the acoustic environment are liftoff and max Q.

Acoustic vibration produces a high energy level over a broad frequency range from approximately 20 to $10,000 \mathrm{~Hz}$. Acoustic energy is the primary forcing function causing higher frequency vibrations of flight equipment such as secondary structure and components. In addition, some equipment is sensitive to direct acoustic impingement. This includes items with high ratios or surface area to mass $\left(>50 \mathrm{in}^{2} / \mathrm{lb}\right)$ which are exposed to direct acoustic impingement such as solar arrays and antennas. [Ref. 14]

The acoustic environment is taken into account throughout the design and test of units and subsystems. The establishment of appropriate vibration test levels at the component level is an important factor in designing for the acoustic environment. Excessively conservative levels can increase the probability of failure while excessively low levels can leave defects undetected. Typical failures in electronic equipment include loose components, detached solder connections, broken leads, cracked connectors and boards and damaged relays. Significant numbers of these types of unit failures are often found in system level acoustic tests even though unit level tests reveal most of the failures.

\section{Random Vibration Environment}

Random vibration is so called because of its source, or driving (forcing) function, is random in nature, and over a given period of time the motion and amplitude does not repeat itself. In contrast sinusoidal (sine) vibration repeats itself in a predictable manner, random vibration is generated by the 
operation of jet engines, rocket motors, both liquid and solid fueled and aerodynamic buffeting from high velocity vehicles such as supersonic aircraft, space shuttle orbiters and rockets for space and military use. Random vibration is applied to the test item continuously and all frequencies are present all the time that the vibration system is operating. Random vibration is not applied to the test item as a sweep.

Random vibration is a damaging environment because it excites all the resonances simultaneously in a component or assembly. It is the continuous excitation of the resonance frequencies that will cause failures. The greater the force and/or time of exposure experienced by the component or assembly, the more damage is likely to occur because the part of the component in resonance will fail in fatigue.

Today all vibration testing laboratories use computer controlled systems to equalize and control the vibration exciters (shakers). Figure 3.1, is a block diagram of a typical system. [Ref. 14] After the operator inputs the test random vibration spectrum, the computerized control system equalizes and controls the vibration system. 


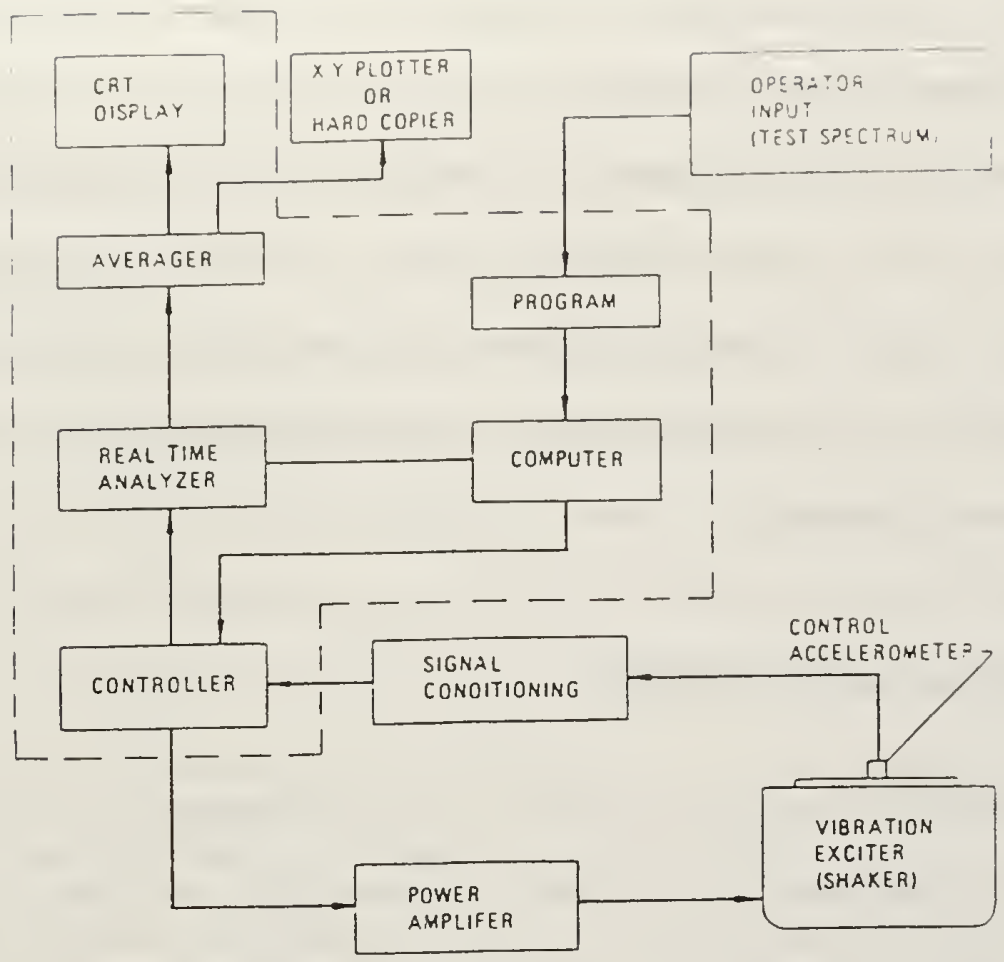

Figure 3.1 Vibration Block Diagram [Ref 14]

The computer-controlled system compares the return signal (feedback) from the control accelerometer with the specified vibration spectrum put into the computer-controlled system by the operator, and corrects the signal to the vibration exciter (shaker) until the return signal from the control accelerometer equals the specified spectrum, within narrow limits.

The time required for the computer-controlled system to equalize the vibration system depends on the complexity of the test item and its fixturing. For a lightweight small test item mounted on a proven fixture the equalization time will be less than a minute. For large, heavy items requiring 
large fixturing equalization can take several minutes. Equalization is accomplished in steps usually starting $12 \mathrm{~dB}$ down from the required grms level and going up in $3 \mathrm{~dB}$ steps until full $(0 \mathrm{~dB})$ is reached. By continuously analyzing the control accelerometer feedback signal and comparing it to the specified spectrum stored in the computer system, the computer continuously attenuates or amplifies each band to keep the signal feedback from the control accelerometer equal to the specified spectrum.

Random vibration is usually quantified in terms of Acceleration Spectral Density (ASD) in $\mathrm{g}^{2} / \mathrm{Hz}$. The ASD is equal to the mean square acceleration $(\mathrm{g} \mathrm{rms})^{2}$ level in a $1 \mathrm{~Hz}$ wide frequency band versus the center frequency of that band. The NASA hitchhiker test level requirement of ASD versus frequency are shown in Figure 3.2.

\section{THERMAL VACCUM TESTING}

Thermal testing of spacecraft components is a major design topic, as it is of vital importance to make sure that all subsystems and components will function in the space thermal environment. The thermodynamic state of a spacecraft is determined by heat irradiation from the sun, albedo and IR from Earth, radiation between the spacecraft's surface and the internal components and heat transfer (conduction and radiation) through internal paths. There is no convection in the vacuum of space, so heat is transferred within the spacecraft by conduction and radiation only.

Throughout all aspects of the spacecraft's mission, which normally covers a wide thermal spectrum, the thermal condition has to be maintained within a specified limit or range, which can only be achieved by a proper thermal control design, be it active or passive. This control has to be accomplished before launch, during ascent into orbit, and throughout all transfers to a final orbit or trajectory.

Since testing under mission conditions allows much more precise statements on the components' function and reliability than simple calculation, space environments have to be simulated. Thermal vacuum testing provides simulation of a mission's thermal spectrum and heat dissipation in a spacecraft, following a pre-defined thermal pattern like the one that is expected 
throughout the spacecraft's mission. The thermal condition of every single part of a subsystem can be measured by thermocouples, and functional tests carried out under space like conditions. Even failures due to material weakness or flawed structural design can be discovered and problems solved before launch. Thermal vacuum testing cannot simulate all influences the spacecraft will be exposed to in space, such as changes in gravity or solar radiation which darkens surfaces and thus changing their thermal properties.

Thermal vacuum testing is performed by means of a Thermal Vacuum Chamber (TVAC). Testing consists of thermal cycling under vacuum conditions. One thermal cycle is performed with dwell times of 60 minutes for each temperature extreme. Normally, maximum and minimum temperatures for thermal vacuum acceptance testing is $5^{\circ} \mathrm{C}$ beyond the predicted maximum thermal ranges expected during flight. Previous thesis research predicted an operating environment of $-17^{\circ} \mathrm{C}$ to $+55^{\circ} \mathrm{C}$. PANSAT will be tested from $-22^{\circ} \mathrm{C}$ to $+60^{\circ} \mathrm{C}$ and at pressures of at least $1 \times 10^{-7}$ Torr. [Ref. 15]

In 1974 MIL-STD-1540A was written to standardize the test requirements and establish a uniform set of definitions, environmental criteria, and test methods for military space vehicles, subsystems and components. This document was in use until 1982, when MIL-STD-1540B was published. MIL-STD-1540B is oriented toward low-risk, long-life space vehicles and provides requirements for component, subsystem, and system-level testing. This includes orbiting vehicles, payloads that perform their mission while attached to recoverable launch vehicles, and airborne support equipment. MIL-STD-1540 states that test requirements should be tailored to the specific space program or project, considering design complexity, state of the art, mission criticality and acceptable risk. 


\section{PANSAT SPECIFIC TESTING}

The scope of these tests is the testing of the Mass Storage Unit (MSU), Electronic Power System (EPS), and Temperature Multiplexing (TMUX) modules. The test sequence, specifications, procedures and documentation are presented in this document. The PANSAT subsystems have been vibration tested in the "Z" or vertical axis at the qualification level, and tested to acceptance standards in the "X" and "Y" directions due to the weight limitations of the shaker equipment. System level testing to qualification levels is planned.

As stated previously, the random vibration tests will simulate elevated levels of the dynamic environment imposed on the satellite during launch. Each subsystem will undergo the random vibration testing in all three axes. The vibration levels for PANSAT follow the levels established by NASA Hitchhiker payload requirements. Subsystems will be tested to NASA specified qualification levels and the completed PANSAT system will be tested to qualification levels. Each subsystem must complete the vibration tests in all axes, and pass visual and functional tests following each vibration test. NASA hitchhiker qualification test levels for STS payloads of ASD versus frequency are shown in Table 3.1, and 3.2.

\begin{tabular}{|c|c|}
\hline Frequency $(\mathrm{Hz})$ & $\begin{array}{c}\text { ASD Level } \\
\left(\mathrm{G}^{2} / \mathrm{Hz}\right)\end{array}$ \\
\hline 20 & .025 \\
\hline $20-50$ & $+6 \mathrm{~dB} /$ oct \\
\hline $50-600$ & .15 \\
\hline $600-2000$ & $-4.5 \mathrm{~dB} / \mathrm{oct}$ \\
\hline 2000 & .025 \\
\hline Overall & $12.9 \mathrm{G}_{\mathrm{ms}}$ \\
\hline
\end{tabular}

Table 3.1 Qualification Spectrum 


\begin{tabular}{|c|c|}
\hline Frequency $(\mathrm{Hz})$ & $\begin{array}{c}\text { ASD Level } \\
\left(\mathrm{G}^{2} / \mathrm{Hz}\right)\end{array}$ \\
\hline 20 & .0125 \\
\hline $20-50$ & $+6 \mathrm{~dB} /$ oct \\
\hline $50-600$ & .075 \\
\hline $600-2000$ & $-4.5 \mathrm{~dB} /$ oct \\
\hline 2000 & .0125 \\
\hline Overall & $9.1 \mathrm{G}_{\mathrm{mms}}$ \\
\hline
\end{tabular}

Table 3.2 Acceptance Spectrum

A testing schedule is used to ensure proper power level sequencing. The durations are required to allow the software to adjust the drive spectrum to create the desired conditions. NASA hitchhiker test requirements are $0 \mathrm{~dB}$ for 1 minute. The durations and test levels tested to are shown in Table 3.3.

\begin{tabular}{|c|c|}
\hline Level dB & Duration \\
\hline-10 & $1 \mathrm{~min}$ \\
\hline-8 & $1 \mathrm{~min}$ \\
\hline-6 & $.5 \mathrm{~min}$ \\
\hline-4 & $.5 \mathrm{~min}$ \\
\hline-2 & $.5 \mathrm{~min}$ \\
\hline 0 & $1 \mathrm{~min}$ \\
\hline Measurement & \\
\hline 0 & $30 \mathrm{sec}$ \\
\hline
\end{tabular}

Table 3.3 Test Levels

NASA has no thermal vacuum testing requirement for the Hitchhiker program. As stated previously, the thermal vacuum test is a test of workmanship intended to evaluate performance of a subsystem and design under the expected severe environmental conditions. Each test article will undergo a total of 2 thermal cycles. Functional tests will be conducted at ambient temperature and at the hot and cold extremes. 
The temperature extremes for the thermal cycles have been determined based on a $5^{\circ} \mathrm{C}$ increase over the estimated operating conditions for the most sensitive components. Previous research has determined that the temperature extremes expected on orbit are approximately $-17^{\circ} \mathrm{C}$ and $+55^{\circ} \mathrm{C}$. [Ref. 15] The target temperatures for the tests are $-22^{\circ} \mathrm{C}$ and $+60^{\circ} \mathrm{C}$. Two thermal cycles were performed on each test item with dwell times of 60 minutes for each temperature extreme. A cycle is defined as beginning at ambient temperature $\left(25^{\circ} \mathrm{C}\right)$, proceeding to the minimum temperature, heating to the maximum temperature, and cooling to ambient temperature again.

Thermal vacuum cycling was done with a target average temperature rise and fall of $1^{\circ} \mathrm{C}$ per minute. This was accomplished through the built-in heating and refrigeration systems of the chamber. Heating and cooling of the test article were provided mainly through radiation.

Vacuum specifications for testing varies for the temperature extremes. At the elevated temperature $\left(+55^{\circ} \mathrm{C}\right)$ a minimum vacuum of $5 \times 10^{-5}$ Torr was maintained for the dwell time. A minimum vacuum of $5 \times 10^{-7}$ Torr was maintained for the low temperature extreme $\left(-22^{\circ} \mathrm{C}\right)$

\section{Functional Tests}

At the completion of each shaker event, and continuously throughout the thermal cycle, functional tests were performed on the subsystem being tested so as to insure it passes each test. These tests were conducted using software and a system controller which simulates the PANSAT onboard computer. The MSU's were operationally check out after every event by checking both the systems static RAM and FLASH memory devices. The system controller both read and wrote instructions to the MSU's to determine if they were operating properly and tell where a failure had occurred if any.

The TMUX's also were checked using the system controller. In these tests the software and controller checked the calibrated resistors to see if they are talking to the system. The 
controller also checks that the TMUX is operating within parameters and will read all channels and convert and display the results to the operator.

The EPS's will be checked to see that after every event the system controller can control the EPS to maintain power control (turn off/on every subsystem), battery control (discharge, charge, trickle charge, and online), watchdog functions, and measurements (volts/currents). 


\section{DESCRIPTION OF TEST EQUIPMENT}

\section{A. THERMAL VACUUM CHAMBER}

The thermal vacuum chamber used for the testing of PANSAT is the Tenney Industries, Model SJr. (Space Junior). It is a precision, bench model, thermal vacuum space simulator used for the development and testing of small components in a simulated space environment. The test chamber is constructed of stainless steel to provide good heat transfer and minimum leak rate. The interior is blackened to permit high radiant energy transfer. The chamber is enclosed in a hermetically sealed, insulated, sheet metal container. Access to the vacuum chamber is through a thermal door. A picture of the test chamber is shown in figure 5.1

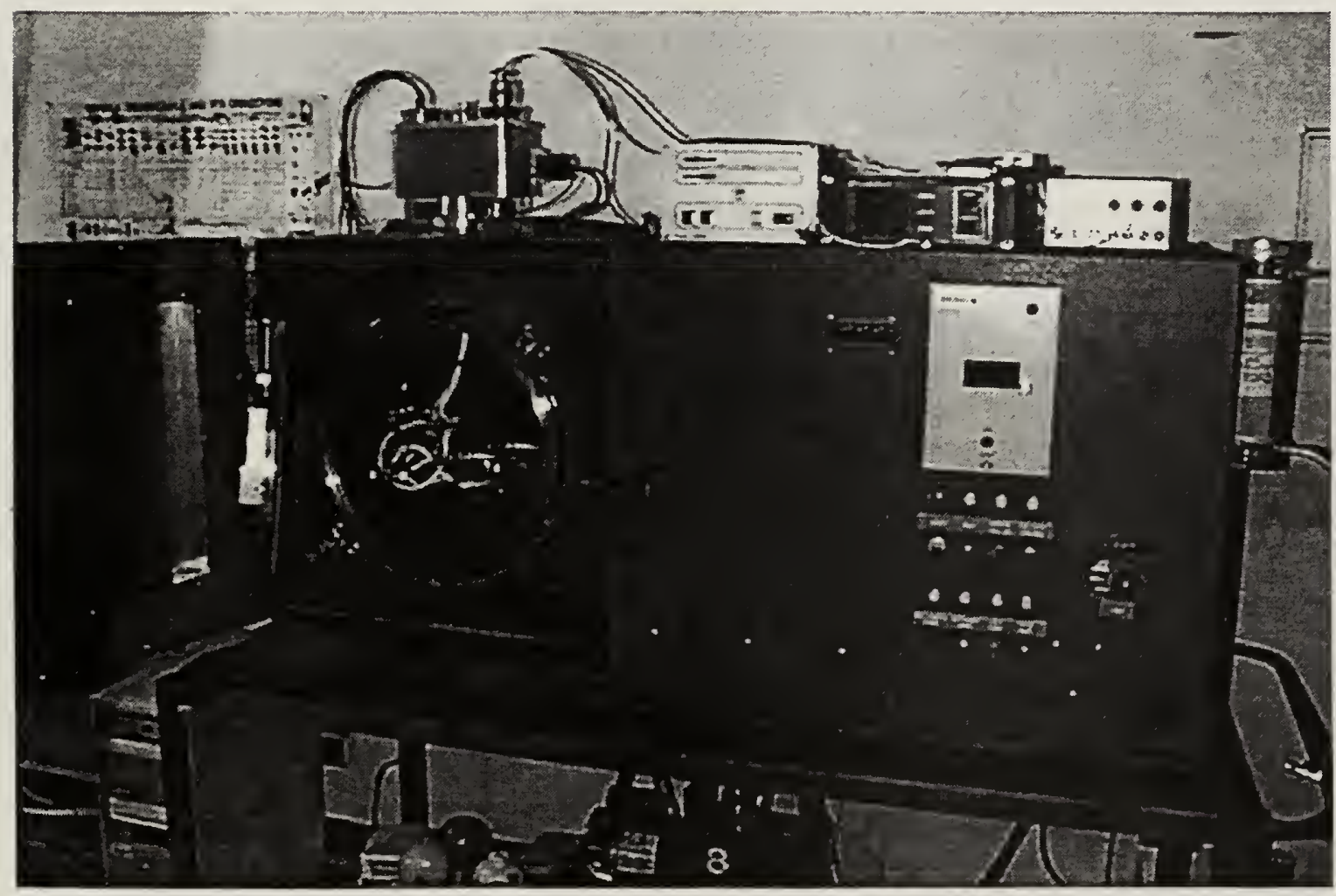

Figure 5.1 Thermal Vacuum Chamber 
The specifications of the thermal vacuum chamber are as follows:

Space Jr. Specifications:

Work Space:

Overall Dimensions:

Vacuum Instrumentation:

Temp. Instrumentation:

Temperature Readout:

Refrigeration:

Two Cold Traps:

$\mathrm{LN}_{2}$ Consumption:

Insulation:

Power Requirements:

Shipping Weight:

Temperature Performance:

Pulldown:

Heatup:
14" Diameter x 12" Deep $(36 \mathrm{~cm} \times 31 \mathrm{~cm})$

56 "W x 26"H x 24"D (142 cm x $66 \mathrm{~cm} \times 61)$

Hot filament ionization and thermocouple gauge

Solid state proportioning controller

Thermocouple wire for use with readout

Cascade System with air-cooled condenser

Mechanically refrigerated and liquid nitrogen $\left(\mathrm{LN}_{2}\right)$

$15 \mathrm{lbs} / \mathrm{hr}$ (cold trap only)

5 " fiberglass

220 Volts, 1 Phase, $60 \mathrm{~Hz}, 30$ Amps

750 lbs. $(240 \mathrm{~kg})$ approx.

$24^{\circ} \mathrm{C}$ to $-45^{\circ} \mathrm{C}$ in approximately 45 minutes

$24^{\circ} \mathrm{C}$ to $-65^{\circ} \mathrm{C}$ in approximately 65 minutes

$24^{\circ} \mathrm{C}$ to $-73^{\circ} \mathrm{C}$ in approximately 90 minutes

$24^{\circ} \mathrm{C}$ to $121^{\circ} \mathrm{C}$ in approximately 30 minutes

$24^{\circ} \mathrm{C}$ to $177^{\circ} \mathrm{C}$ in approximately 60 minutes 
Vacuum Performance:

Temperature

Vacuum

$24^{\circ} \mathrm{C}$ to $-73^{\circ} \mathrm{C}$

$24^{\circ} \mathrm{C}$ to $177^{\circ} \mathrm{C}$

$24^{\circ} \mathrm{C}$ to $177^{\circ} \mathrm{C}$

$24^{\circ} \mathrm{C}$ to $-73^{\circ} \mathrm{C}$

$24^{\circ} \mathrm{C}$ to $-73^{\circ} \mathrm{C}$
100 microns

150 microns

$1.0 \times 10^{-5}$ microns 6 hour

Diffusion Pump

(with mechanical trap)

Diffusion Pump

(with $\mathrm{LN}_{2}$ trap)
Time to evacuate

1 hour

1 hour

Temperature conditioning is accomplished by means of refrigerating tubing and electric heaters thermally bonded to the chamber walls. A hermetically sealed cascade refrigeration system is used to provide sub-ambient temperatures. A solid-state proportioning controller is provided to control the test chamber wall temperature.

The vacuum system consists of a turbo molecular pump and a rotary mechanical pump. A panel mounted valve is provided for venting and backfilling gaseous $\mathrm{N}_{2}$. A high capacity, liquid nitrogen cooled baffle is also provided. A hot filament ionization gauge with dual tungsten elements is provided to monitor chamber pressure. It is readable from $1 \times 10^{-3}$ to $2 \times 10^{-9}$ Torr. A thermocouple gauge is provided for reading fore pressure.

\section{B RANDOM VIBRATION SHAKER}

The shaker used for the testing of PANSAT is the MB Dynamics Model PM500A vibration shaker. It is designed for the testing of small components, subassemblies and small structures. A Model PM500A power amplifier is used for driving the shaker. These two systems in addition to a workstation and specialized software make up the vibration test setup. The specifications for the Model PM500A shaker are as follows. 
Model PM500A Shaker Specifications

Exciter Weight:

420 pounds

Height:

20.3 inches

Force Output:

465 pounds (peak)

Velocity:

60 inches/second

Frequency range:

DC $-3000 \mathrm{~Hz}$

Mounting Area:

13 inches $^{2}$

A schematic of the shaker setup is shown in Figure 5.2. The " $Z$ " direction is in the vertical axis, and "X" " $Y$ " were in the horizontal direction as shown.

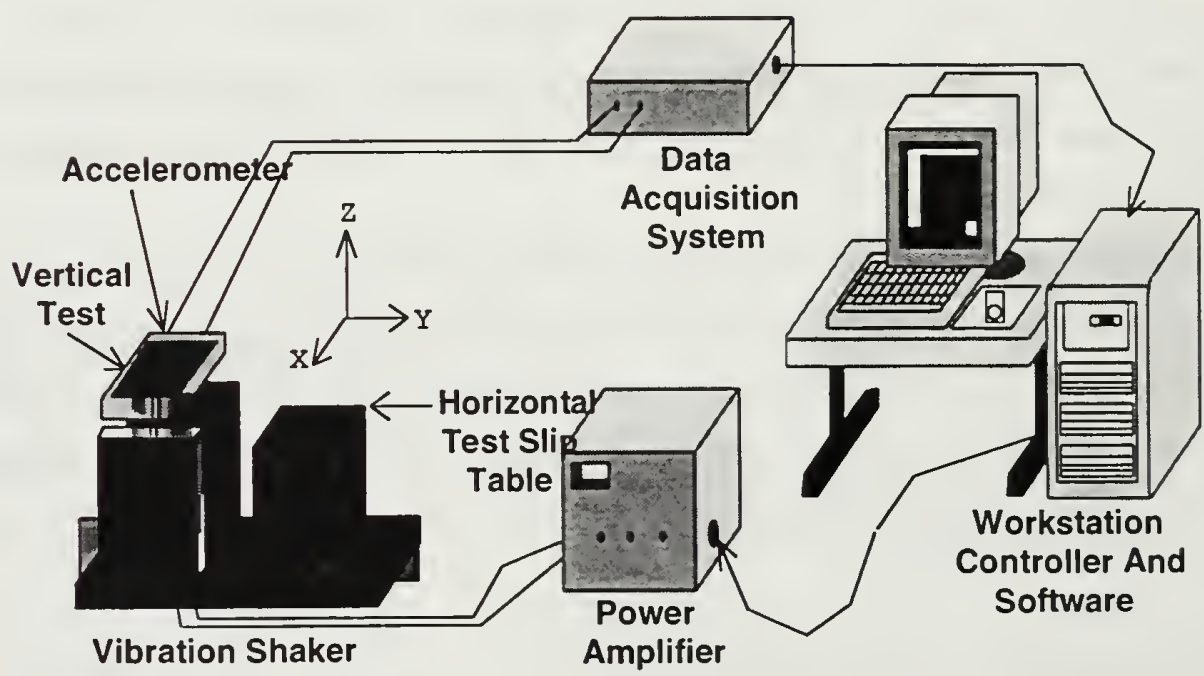

Figure 5.2 Vibration Test Setup (Courtesy of Dan Sakoda) 


\section{TEST RESULTS AND CONCLUSIONS}

The MSU, TMUX, and EPS subsystem were subjected to thermal vacuum testing and random vibration testing between August 22, 1997 and December 9, 1997. All subsystems were subjected to NASA Hitchhiker qualification standards where possible. Due to weight limitations of the shaker the subsystems were tested in the $\mathrm{X}$ and $\mathrm{Y}$ directions to acceptance standards. The table 6.1 shows the test schedule for the vibration testing. Table 6.2 shows the thermal vacuum testing schedule.

\begin{tabular}{|c|c|c|c|}
\hline DATE & SUBSYSTEM & TEST LEVEL & DIRECTION \\
\hline 22 August 1997 & Mass Storage Unit \#1 & Acceptance & Z \\
\hline 25 August 1997 & Mass Storage Unit \# 1 & Acceptance & $\bar{Y}$ \\
\hline 25 August 1997 & Mass Storage Unit \#1 & Acceptance & $\mathrm{X}$ \\
\hline 21 October 1997 & Mass Storage Unit \#2 & Acceptance & $\bar{Y}$ \\
\hline 22 October 1997 & Mass Storage Unit \#2 & Acceptance & $\bar{X}$ \\
\hline 20 November 1997 & Mass Storage Unit \#2 & Qualification & $\mathrm{Z}$ \\
\hline 19 November 1997 & TMUX \#1 & Acceptance & $\mathrm{Z}$ \\
\hline 24 November 1997 & TMUX \#1 & Acceptance & $\mathrm{Y}$ \\
\hline 24 November 1997 & TMUX \#1 & Acceptance & $\mathrm{X}$ \\
\hline 20 November 1997 & TMUX \#2 & Qualification & $\mathrm{Z}$ \\
\hline 24 November 1997 & TMUX \#2 & Acceptance & $\mathrm{Y}$ \\
\hline 24 November 1997 & TMUX \#2 & Acceptance & $\mathrm{X}$ \\
\hline 03 December 1997 & EPS \#1 & Qualification & $\mathrm{Z}$ \\
\hline 04 December 1997 & EPS \#1 & Acceptance & $\mathrm{Y}$ \\
\hline 04 December 1997 & EPS \#1 & Acceptance & $\bar{X}$ \\
\hline
\end{tabular}

Table 6.1 Vibration Test Schedule 


\begin{tabular}{|c|c|}
\hline DATE & SUBSYSTEM \\
\hline 27 AUGUST 1997 & MASS STORAGE UNIT \#1 CYCLE 1 \\
\hline 29 AUGUST 1997 & MASS STORAGE UNIT \#1 CYCLE 2 \\
\hline 24 OCTOBER 1997 & MASS STORAGE UNIT \#2 CYCLE 1 \\
\hline 29 OCTOBER 1997 & MASS STORAGE UNIT \#2 CYCLE 2 \\
\hline 02 DECEMBER 1997 & TMUX \#1 CYCLE 1 \\
\hline 03 DECEMBER 1997 & TMUX \#1 CYCLE 2 \\
\hline 04 DECEMBER 1997 & TMUX \#2 CYCLE 1 \\
\hline 05 DECEMBER 1997 & TMUX \#2 CYCLE 2 \\
\hline 09 DECEMBER 1997 & EPS \#1 CYCLE 1 \\
\hline 11 DECEMBER 1997 & EPS \#1 CYCLE 2 \\
\hline
\end{tabular}

Table 6.2 Thermal Vacuum Schedule

Prior to integration into the Hitchhiker canister the integrated PANSAT system needs to be tested to NASA qualification levels. Pending results from that test, to date the tested subsystems have successfully completed all functional test requirements. Printouts of test results can be seen on the following pages. 


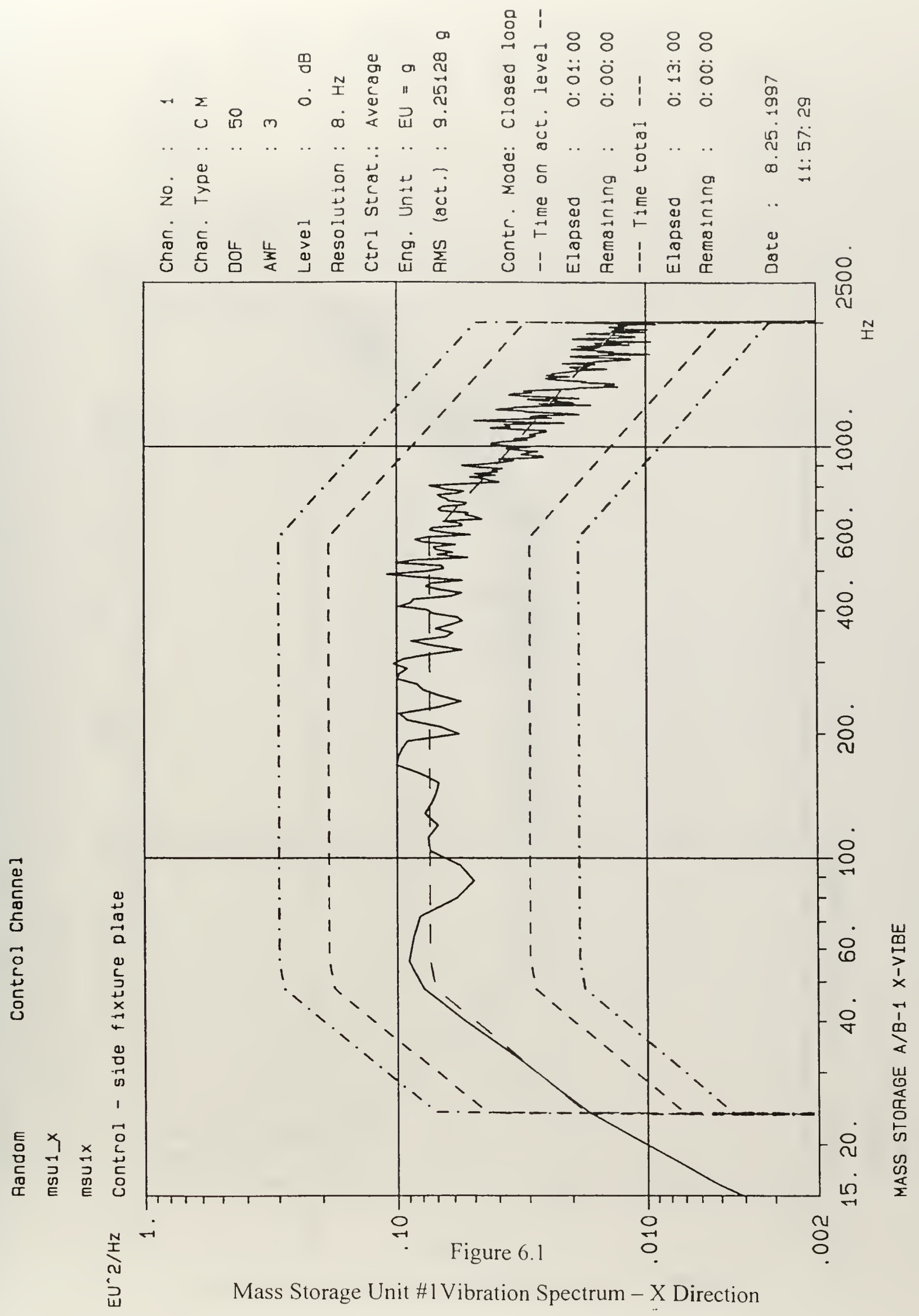




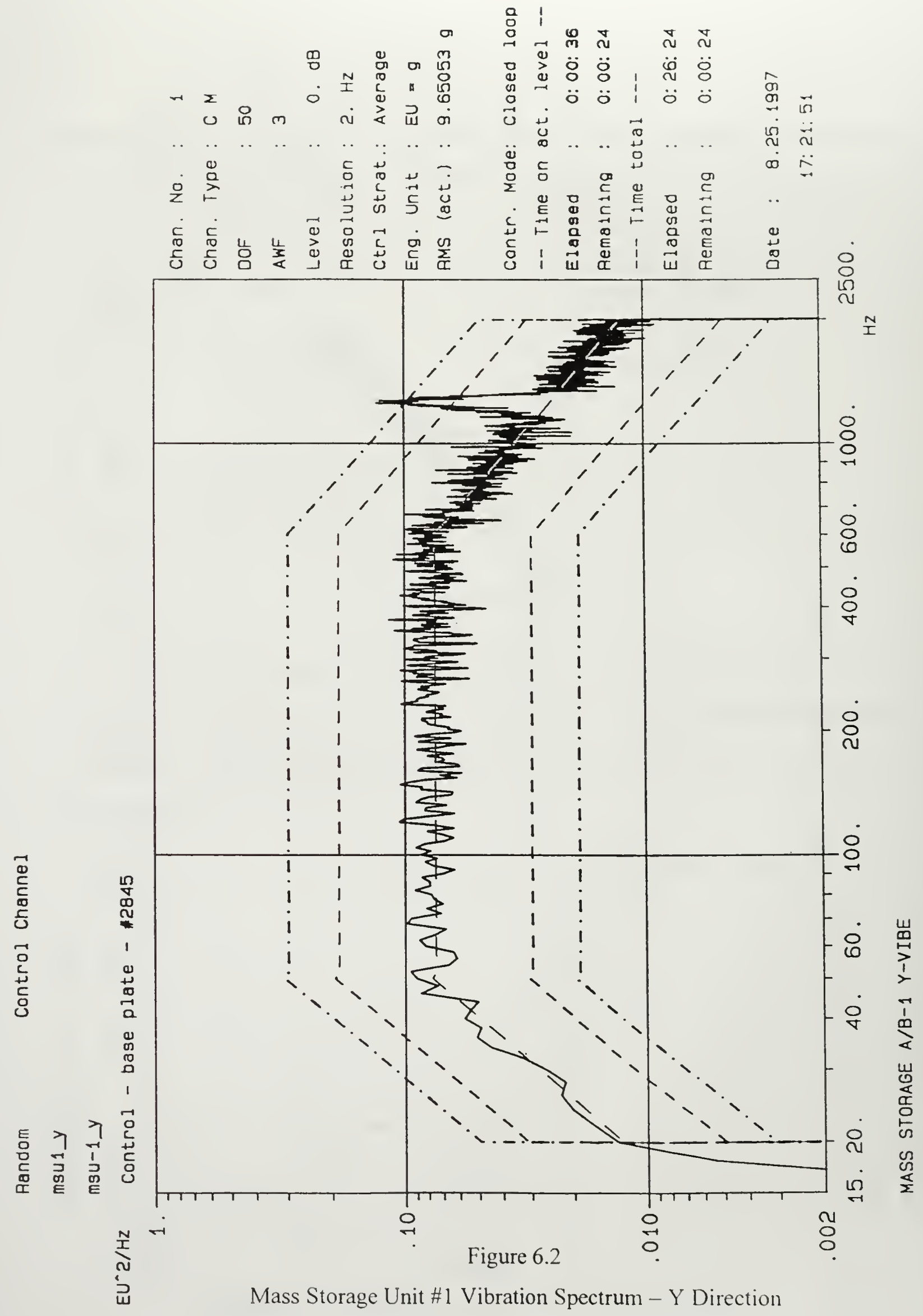




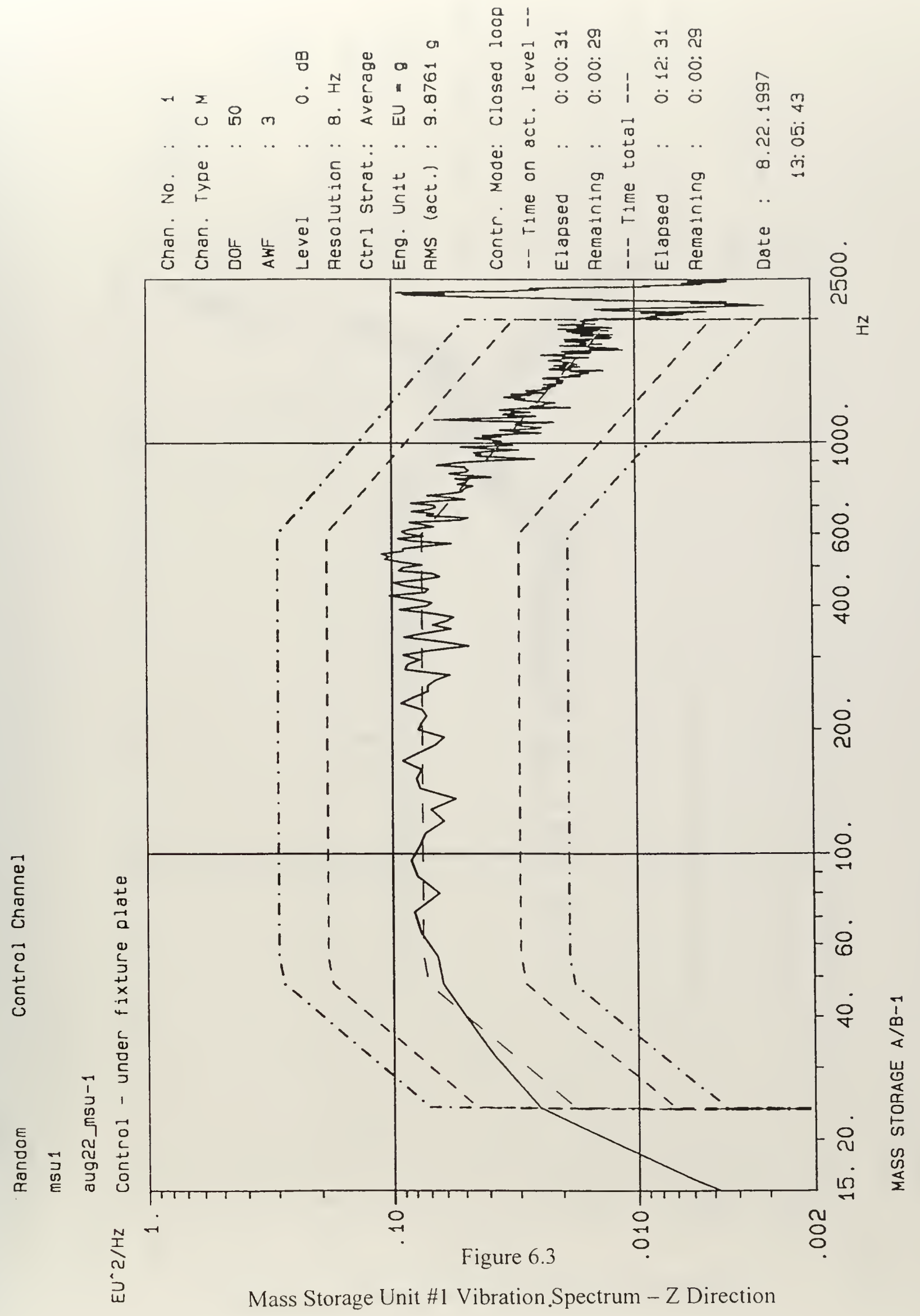




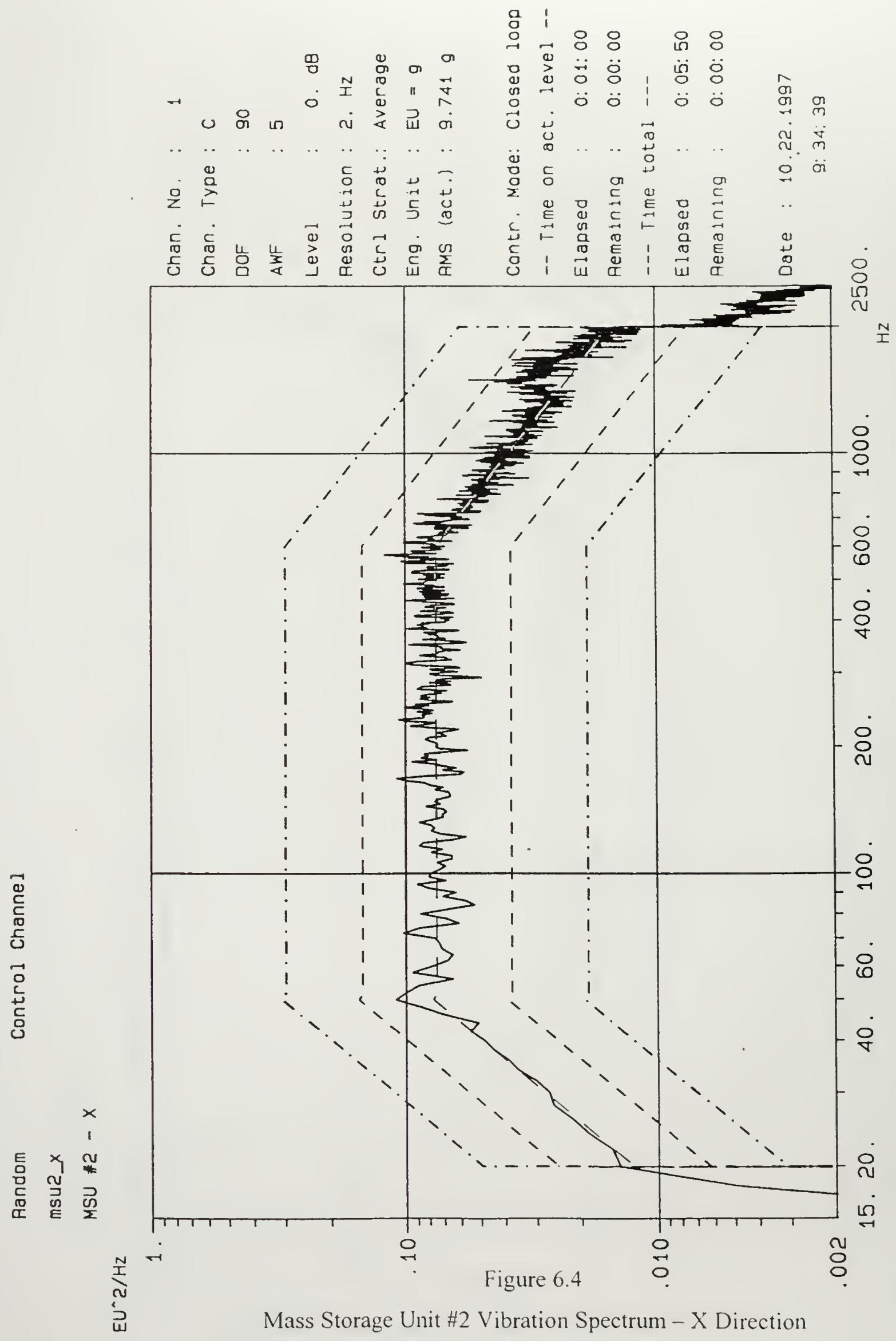




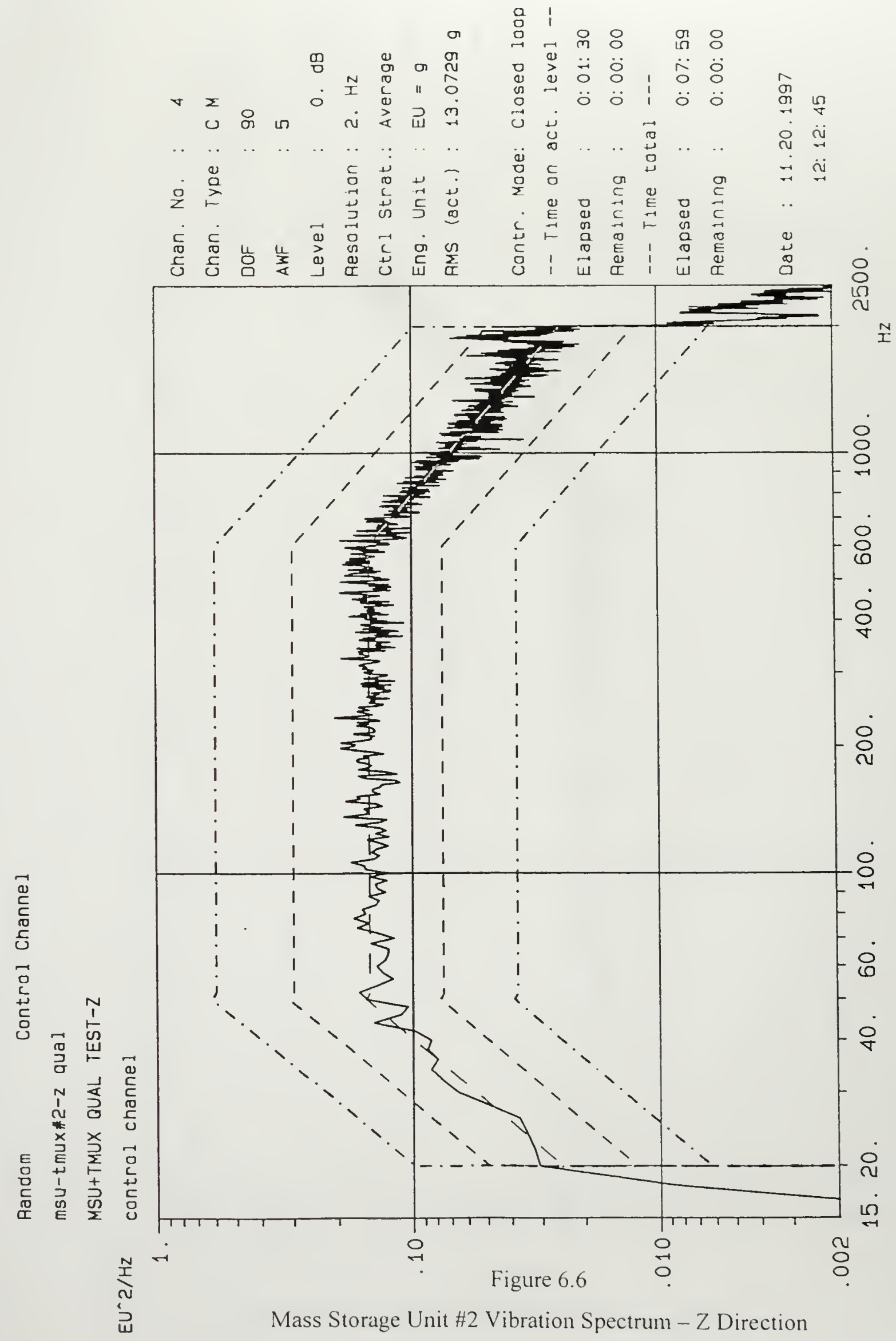




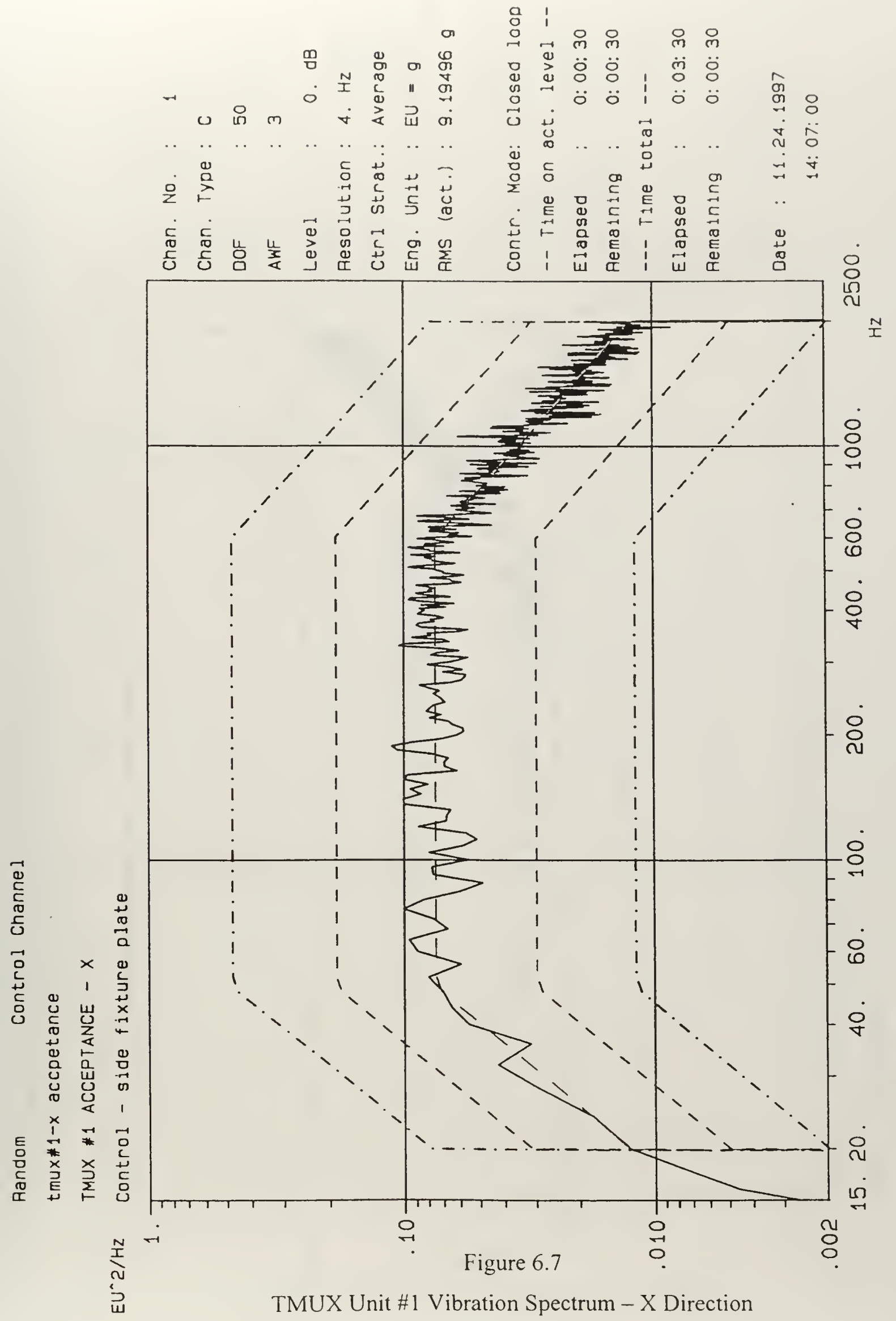




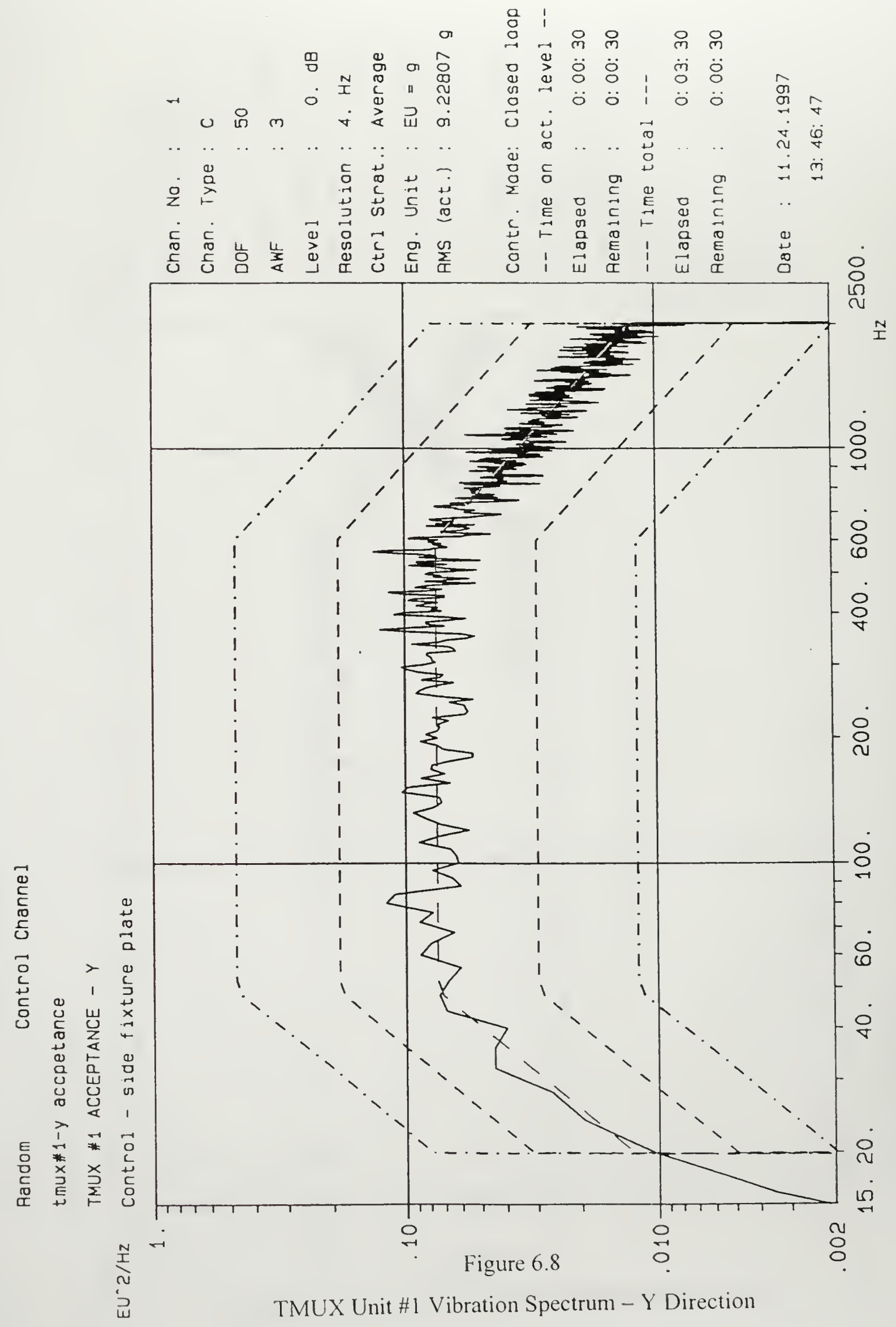




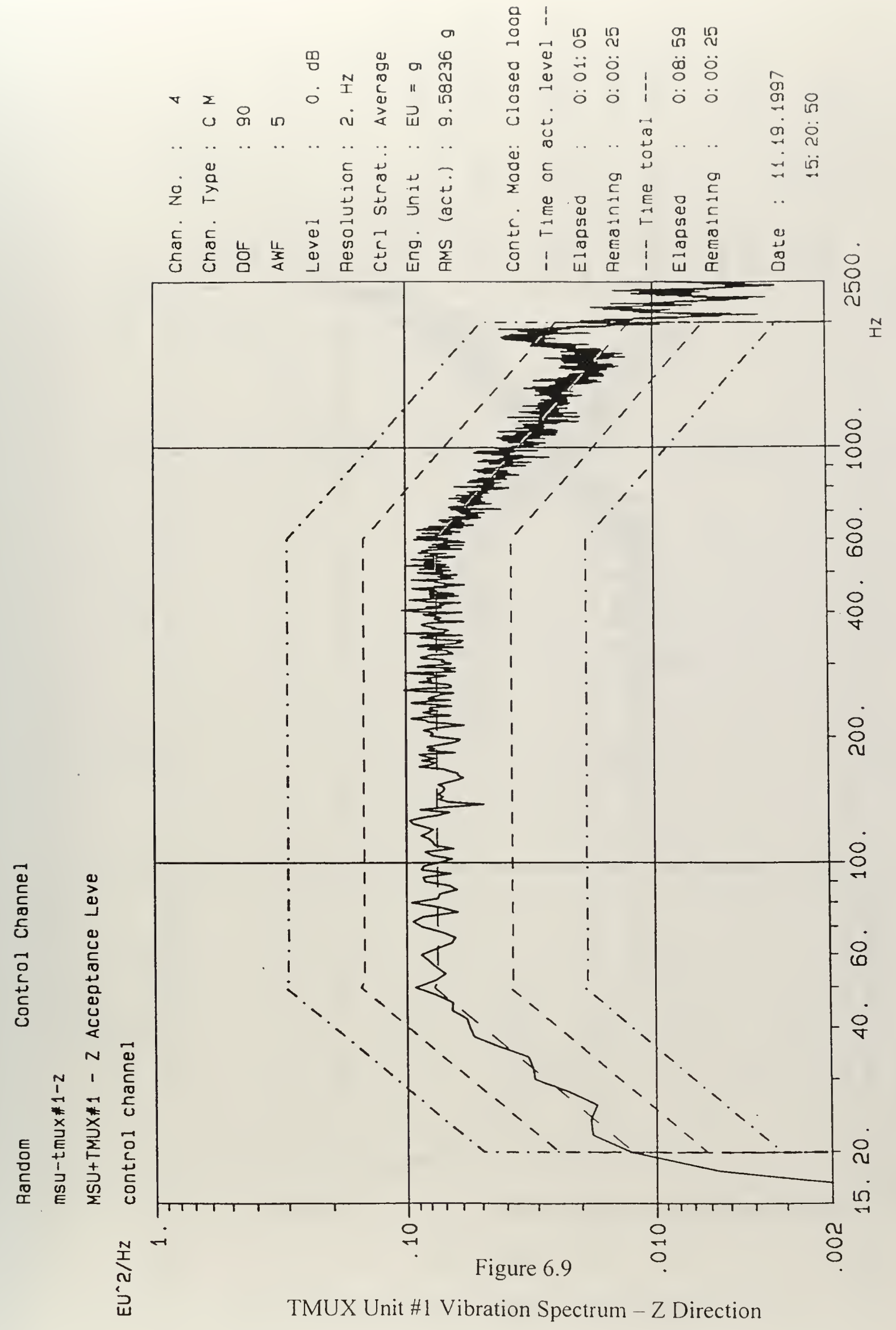




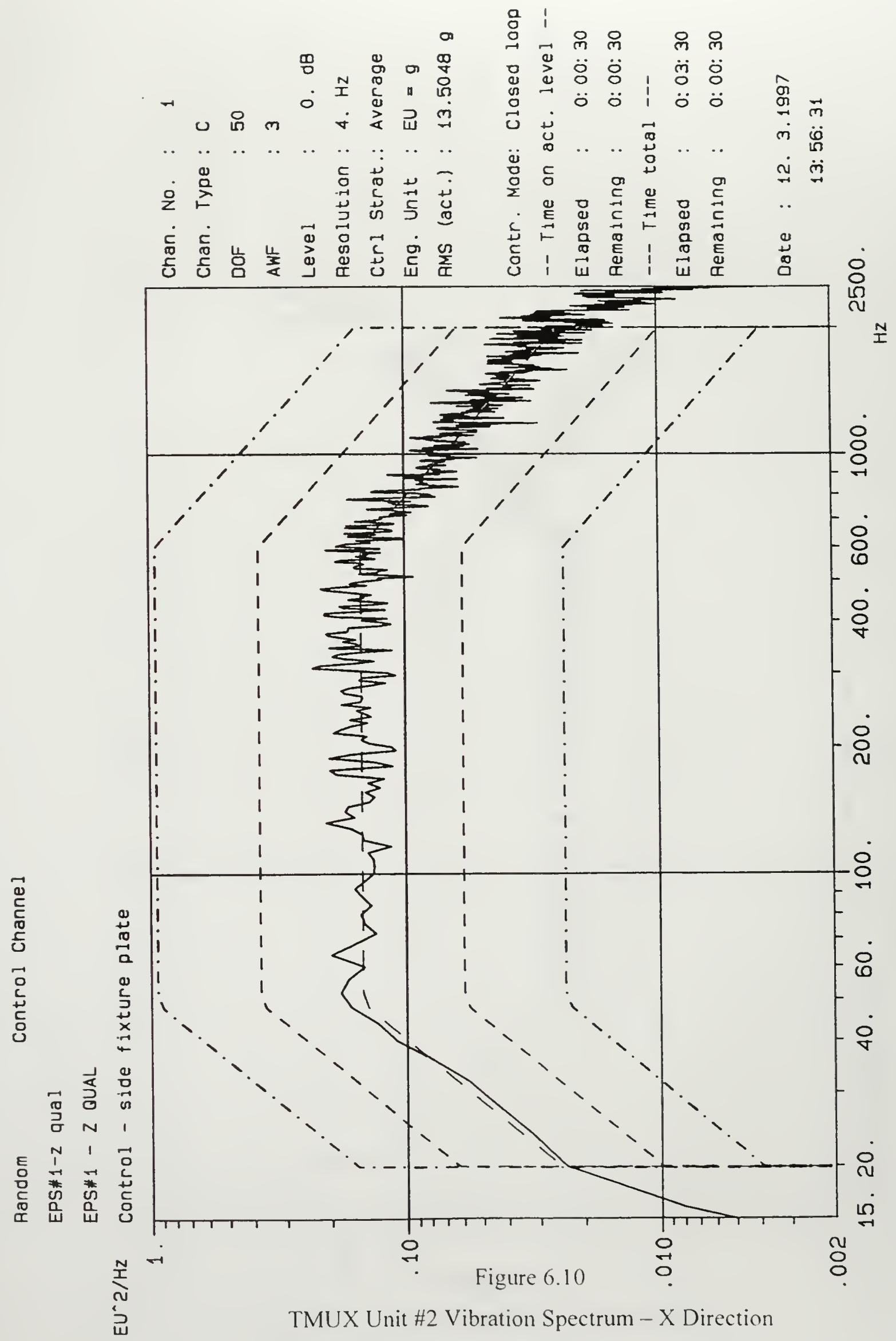




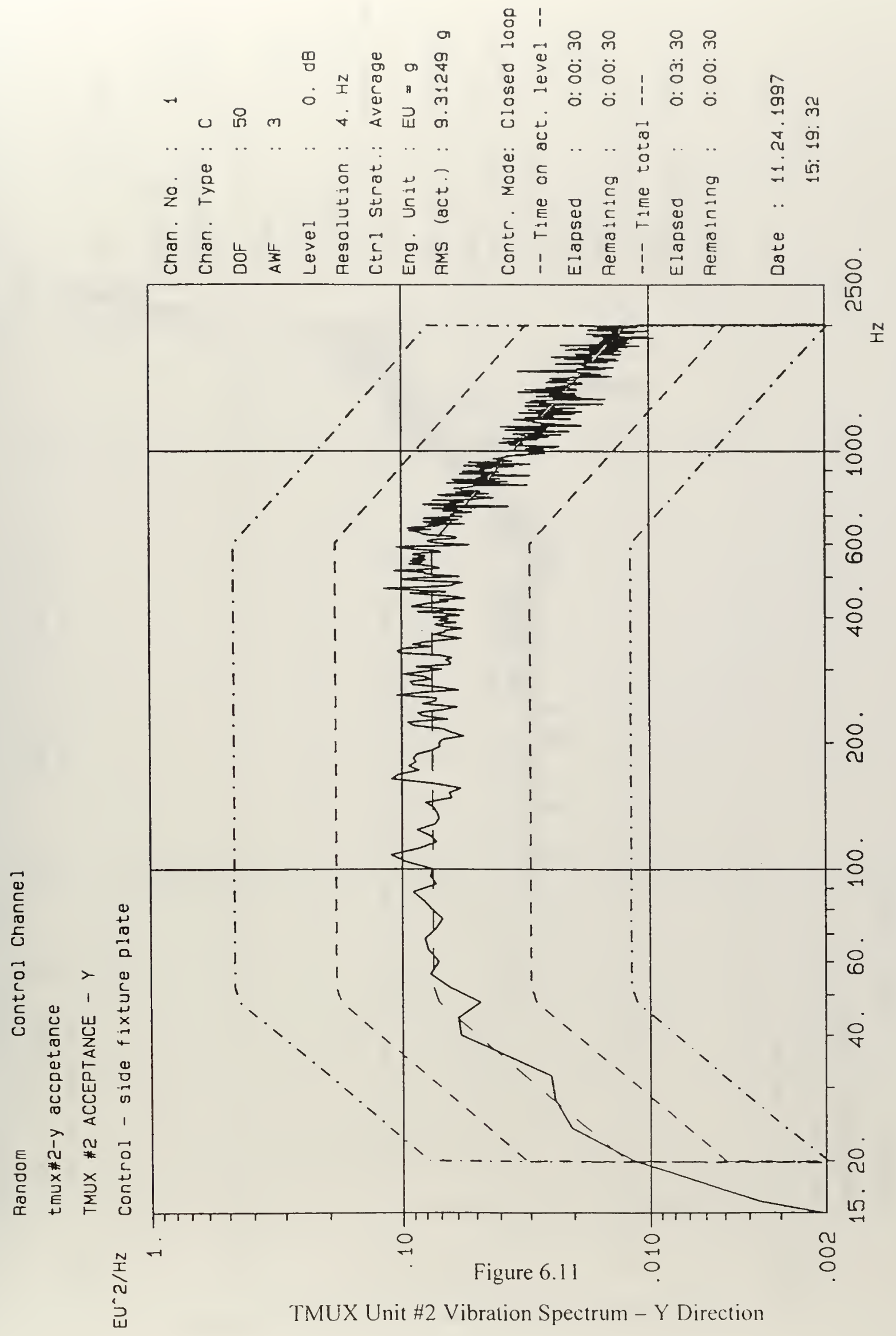




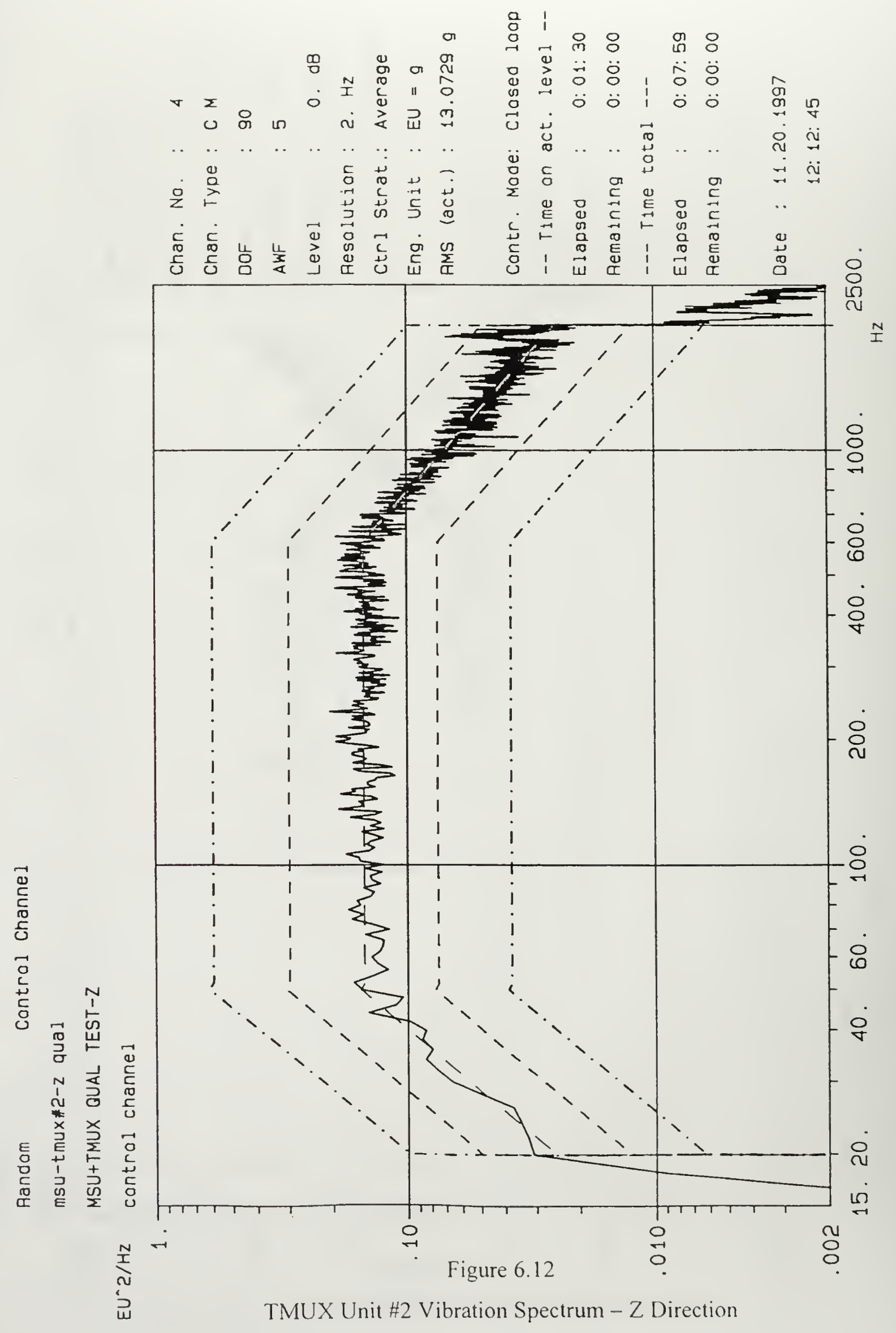




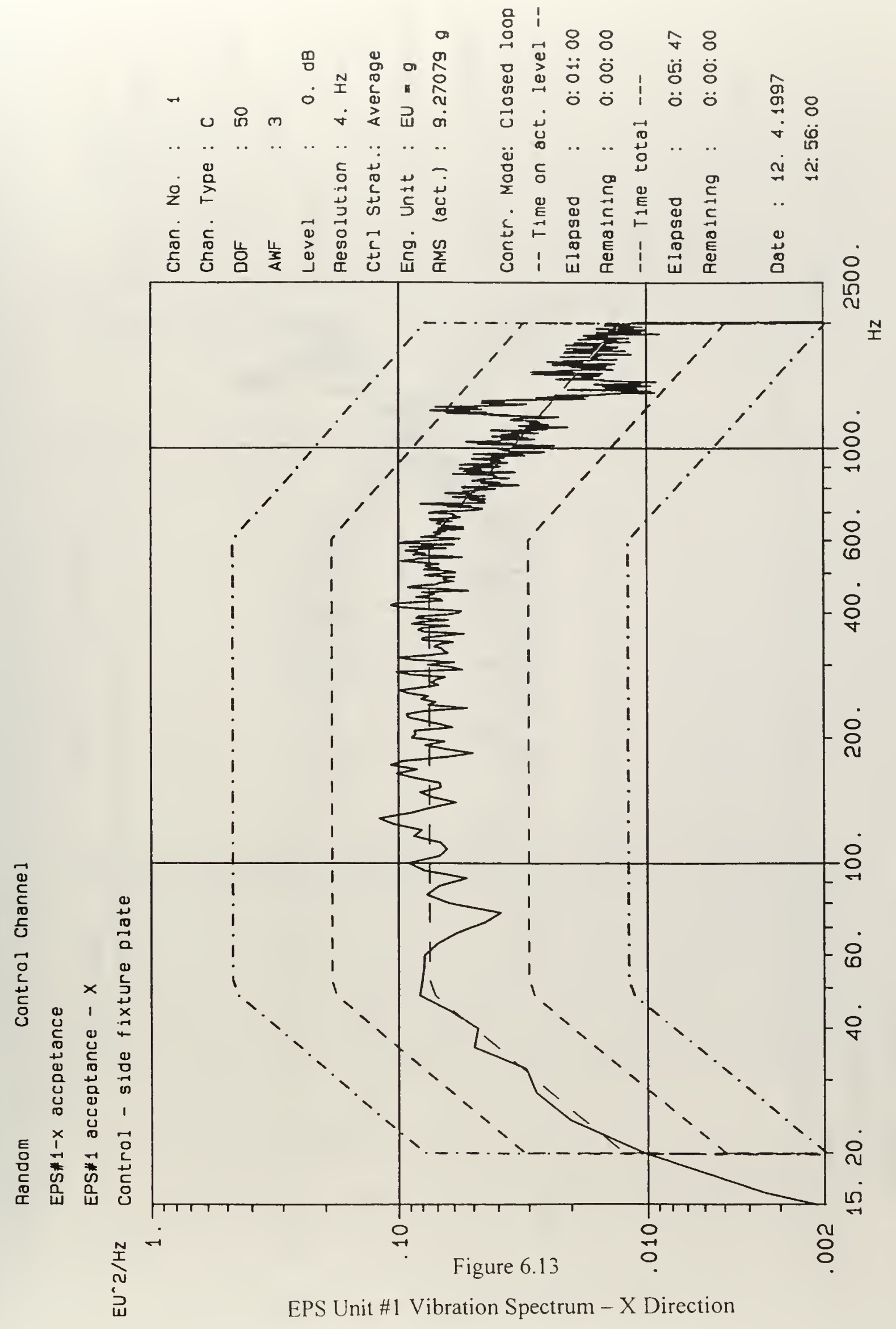




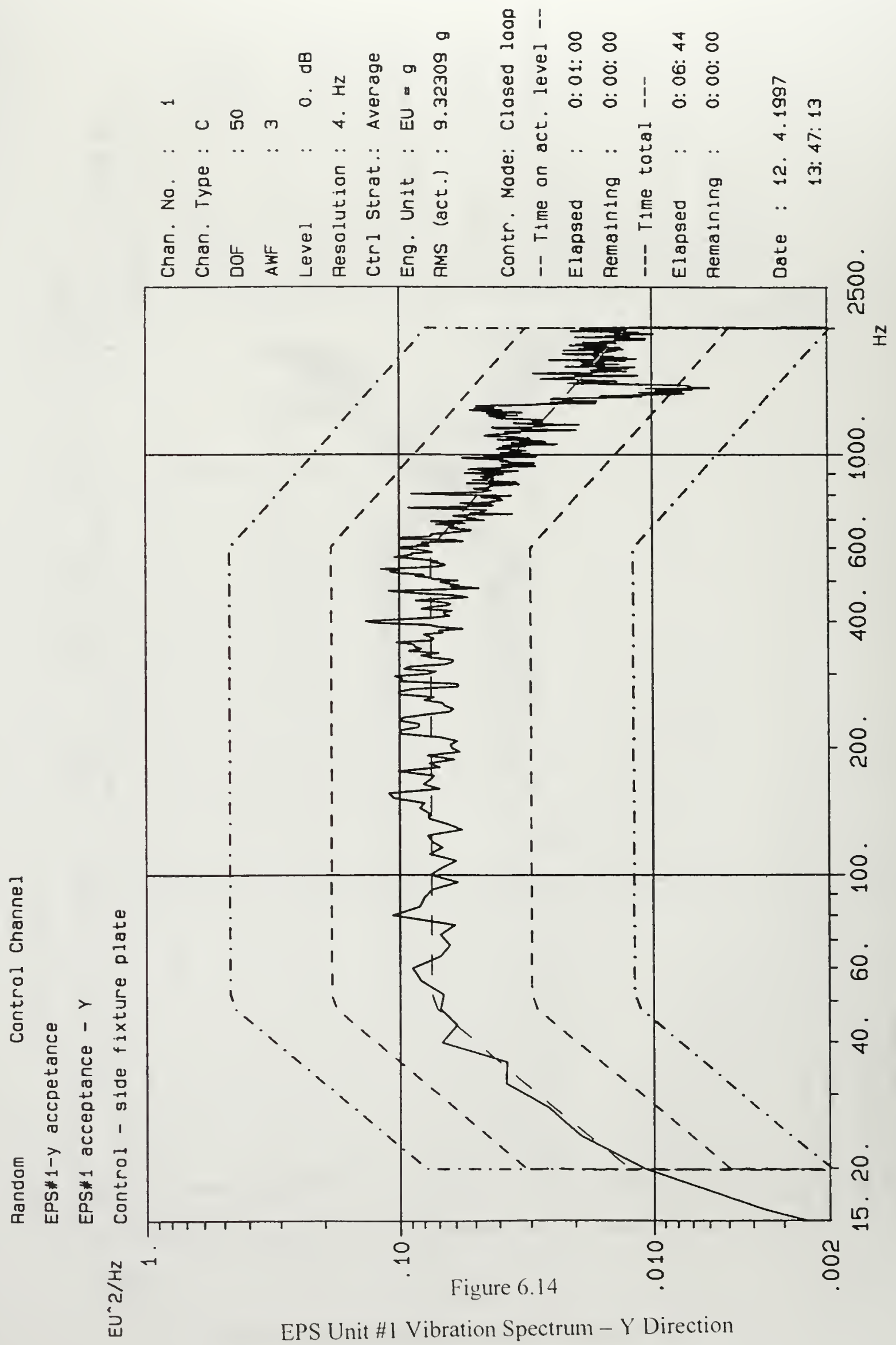




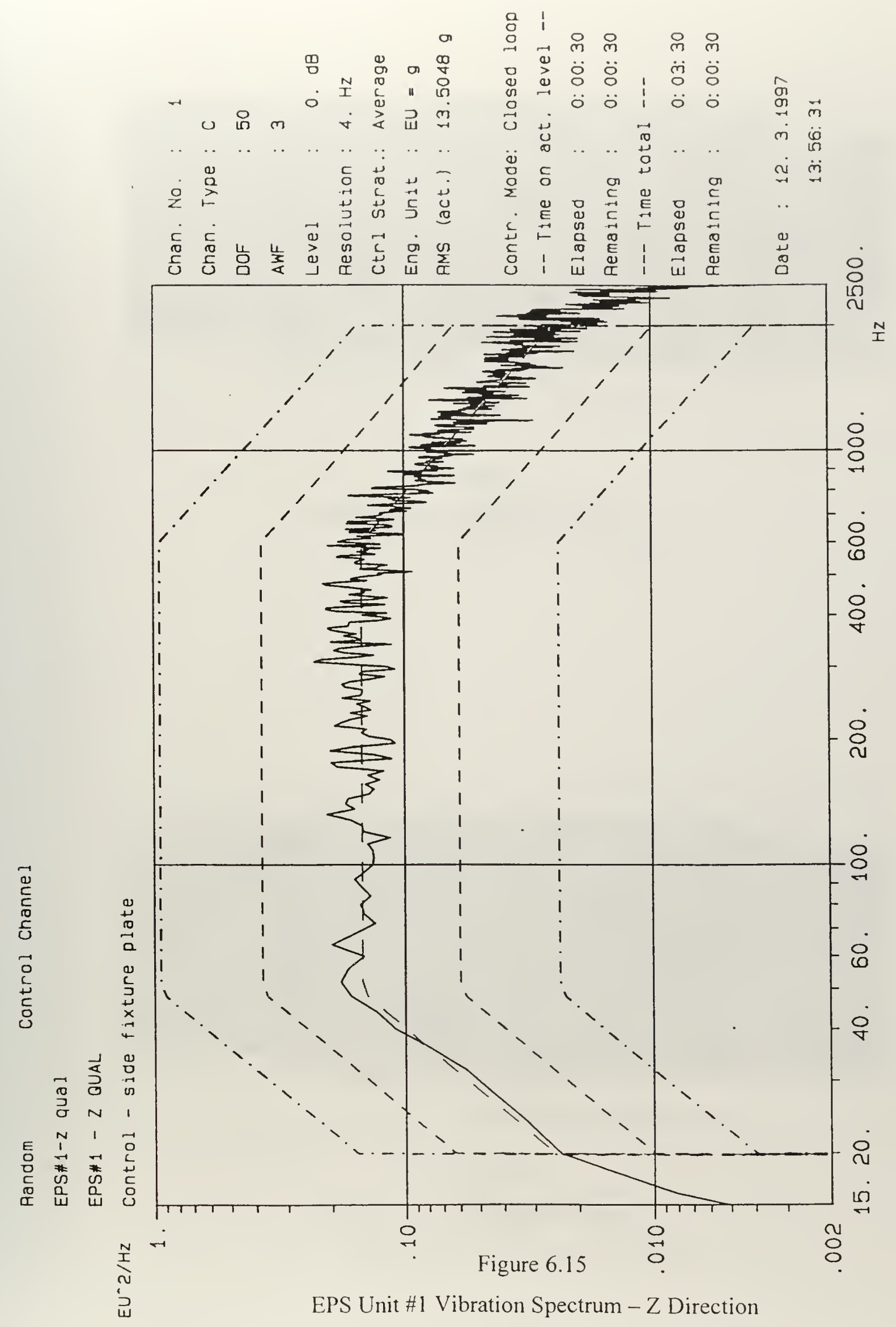




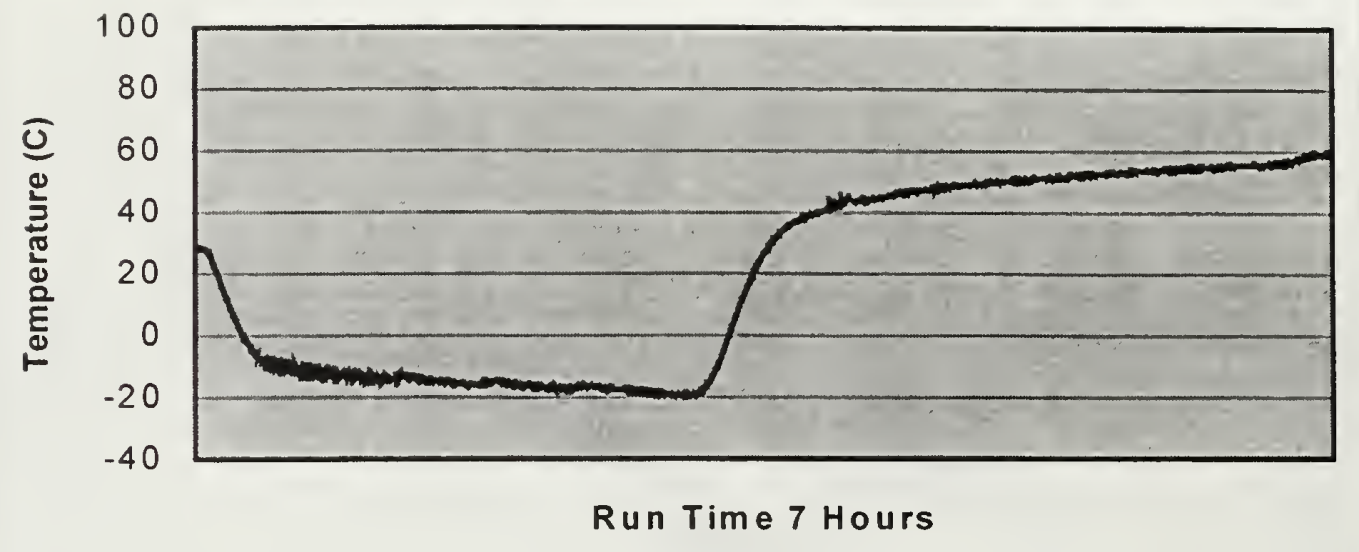

Figure 6.16

MSU \#1 Thermal Vacuum Run \#1

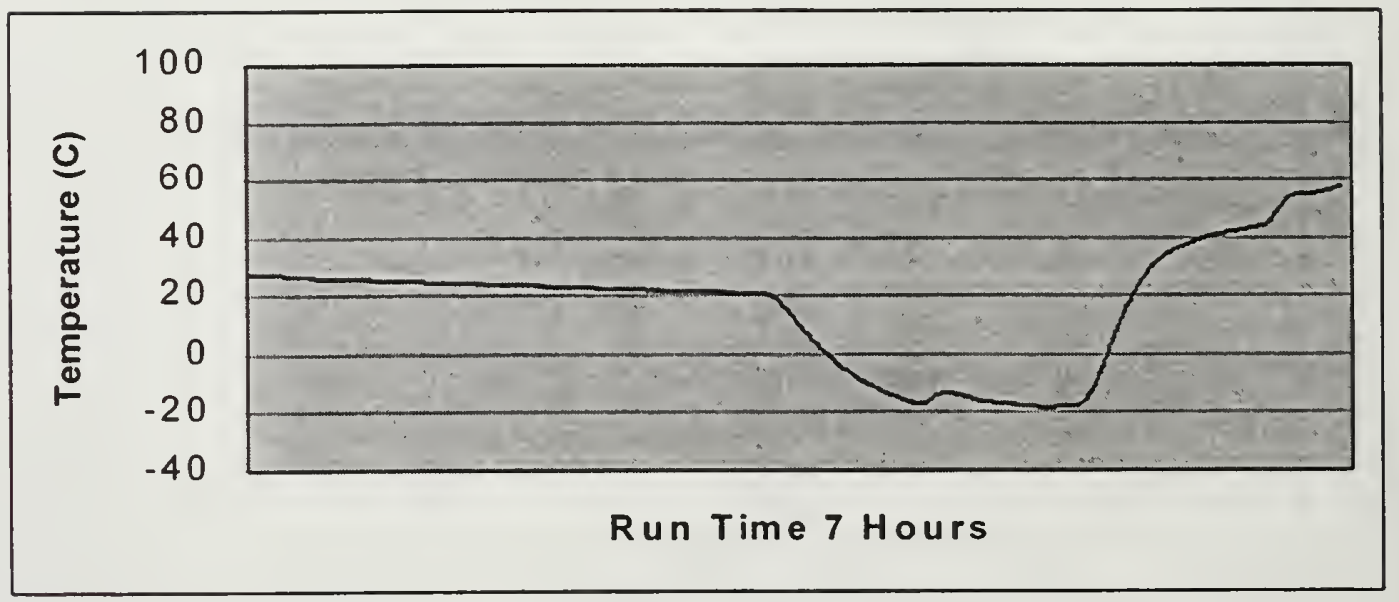

Figure 6.17

MSU \#1 Thermal Vacuum Run \#2 


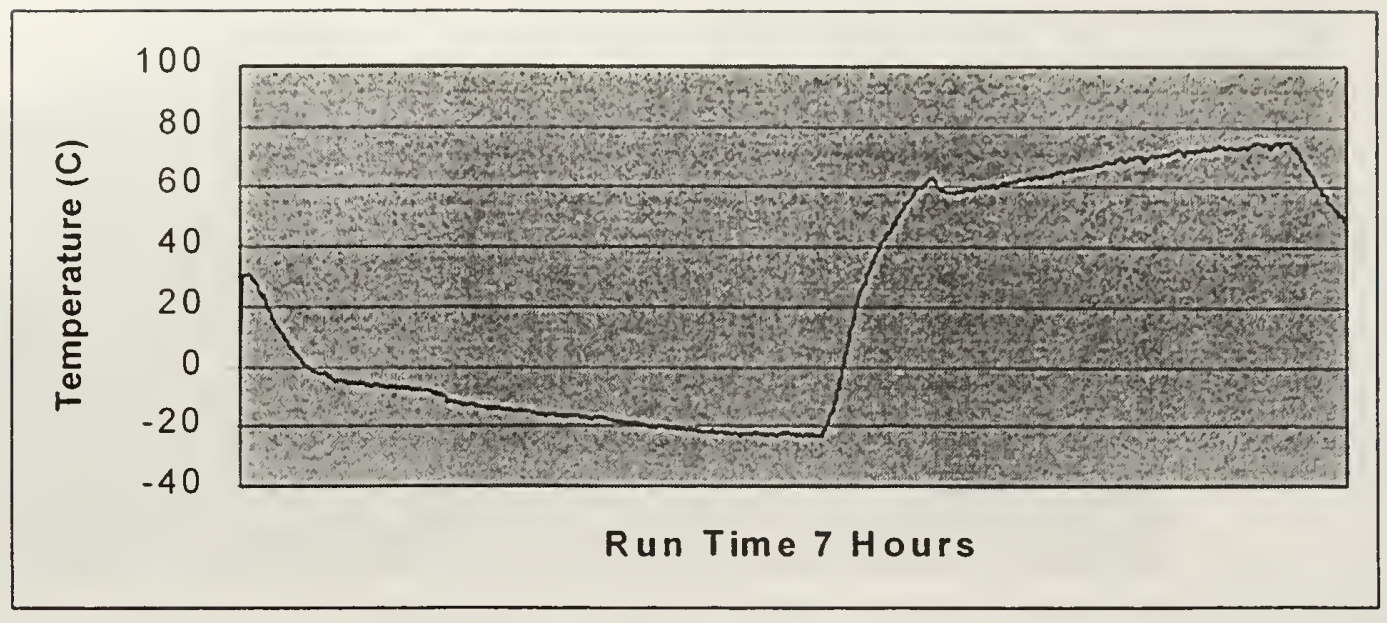

Figure 6.18

MSU \#2 Thermal Vacuum Run \#1

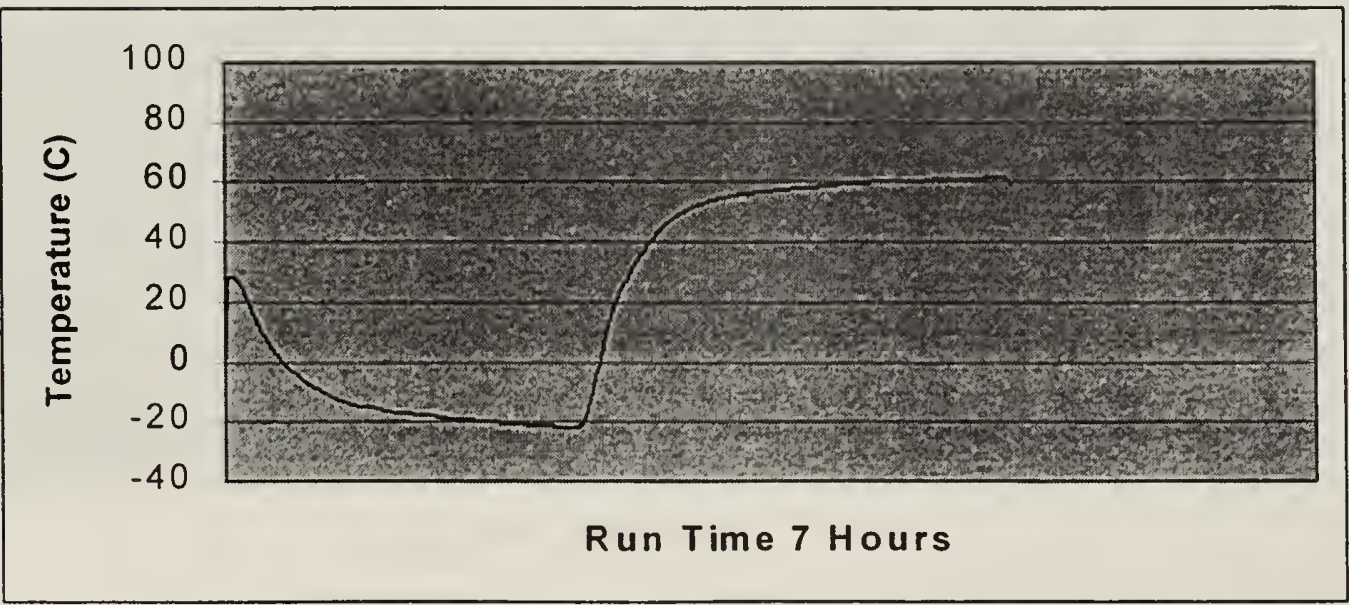

Figure 6.19

MSU \#2 Thermal Vacuum Run \#2 


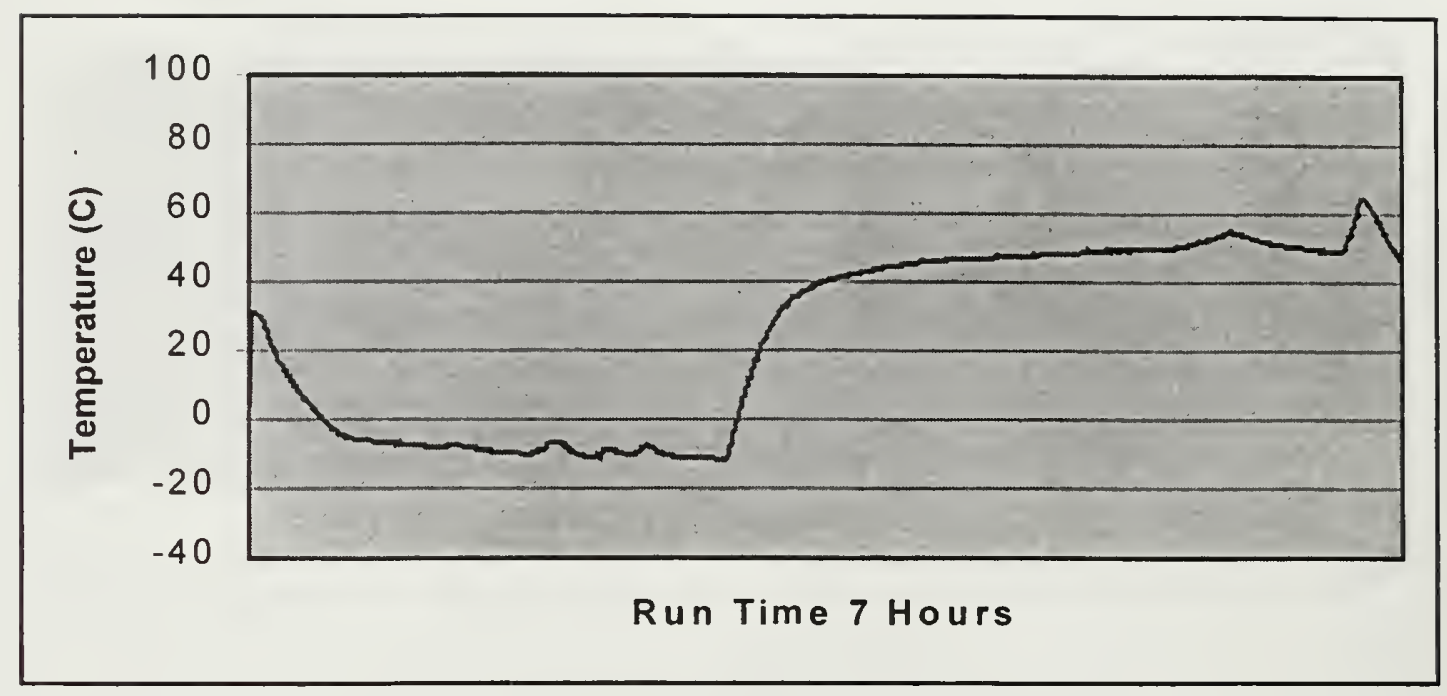

Figure 6.20

TMUX \#1 Thermal Vacuum Run \#1

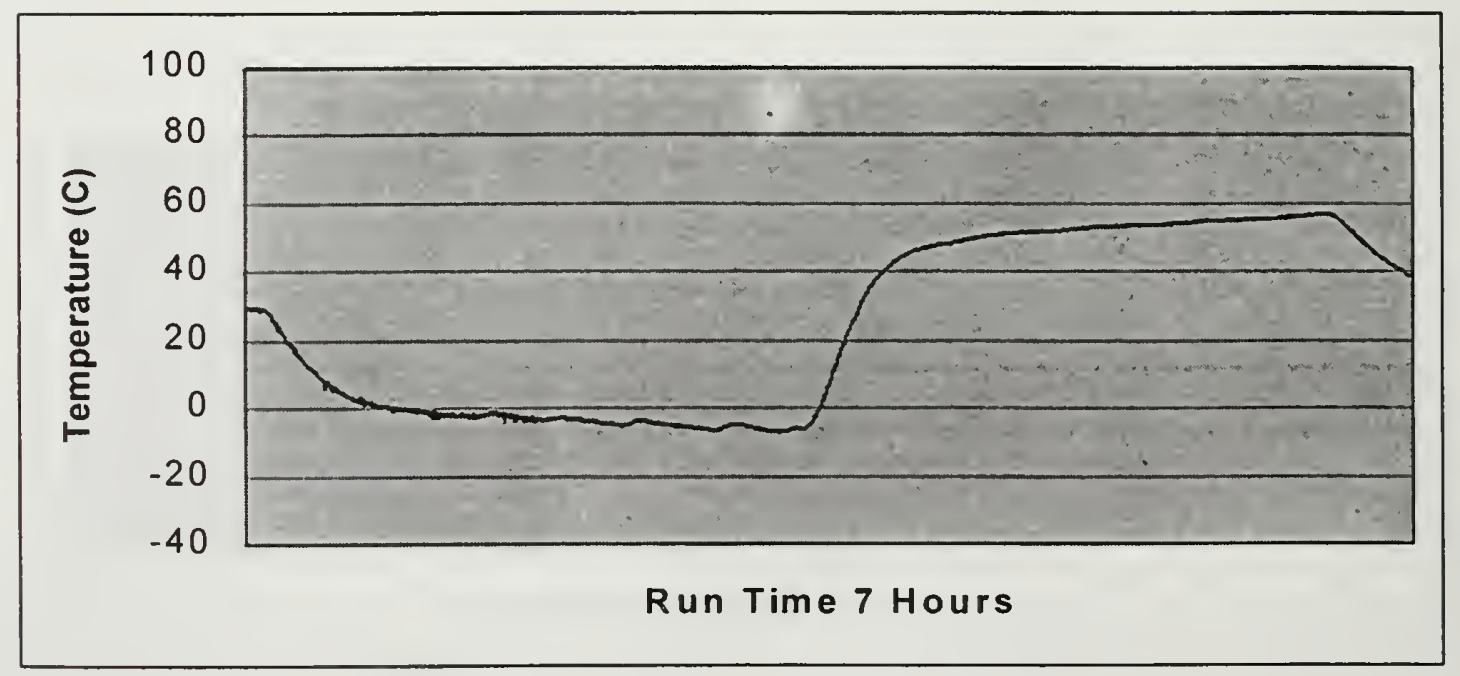

Figure 6.21

TMUX \#1 Thermal Vacuum Run \#2 


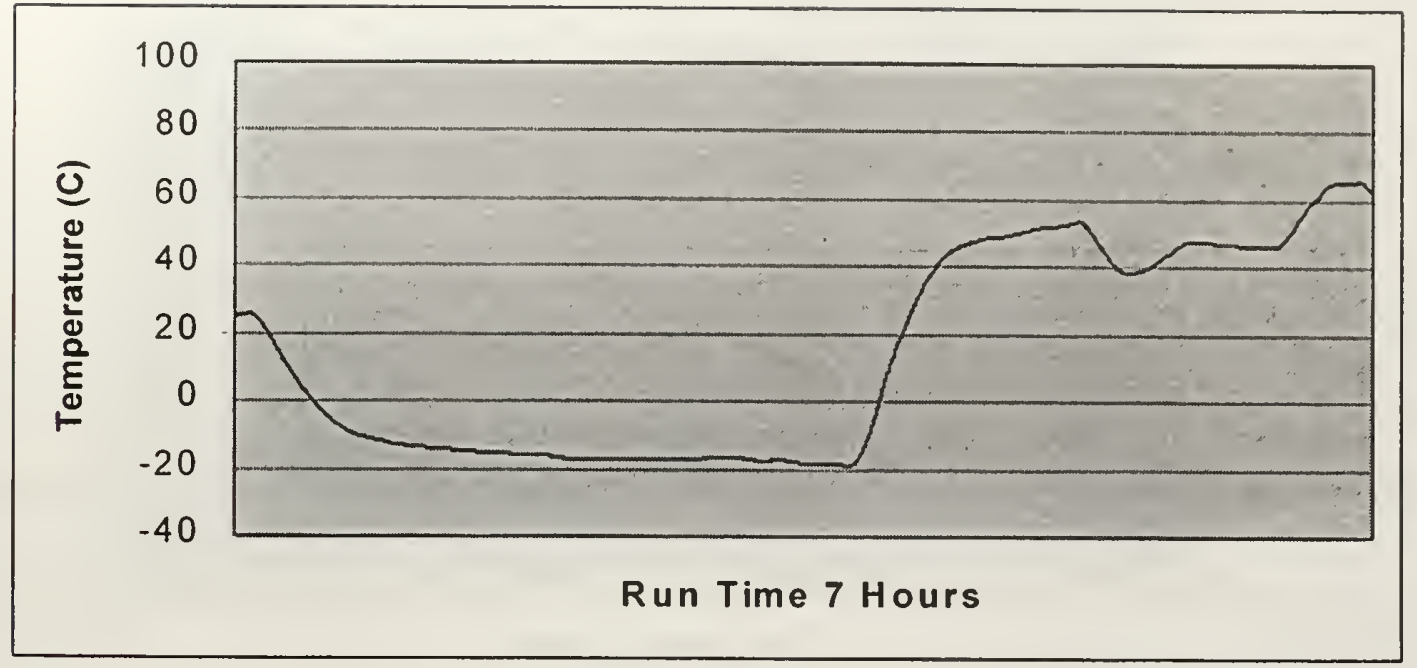

Figure 6.22

TMUX \#2 Thermal Vacuum Run \#1

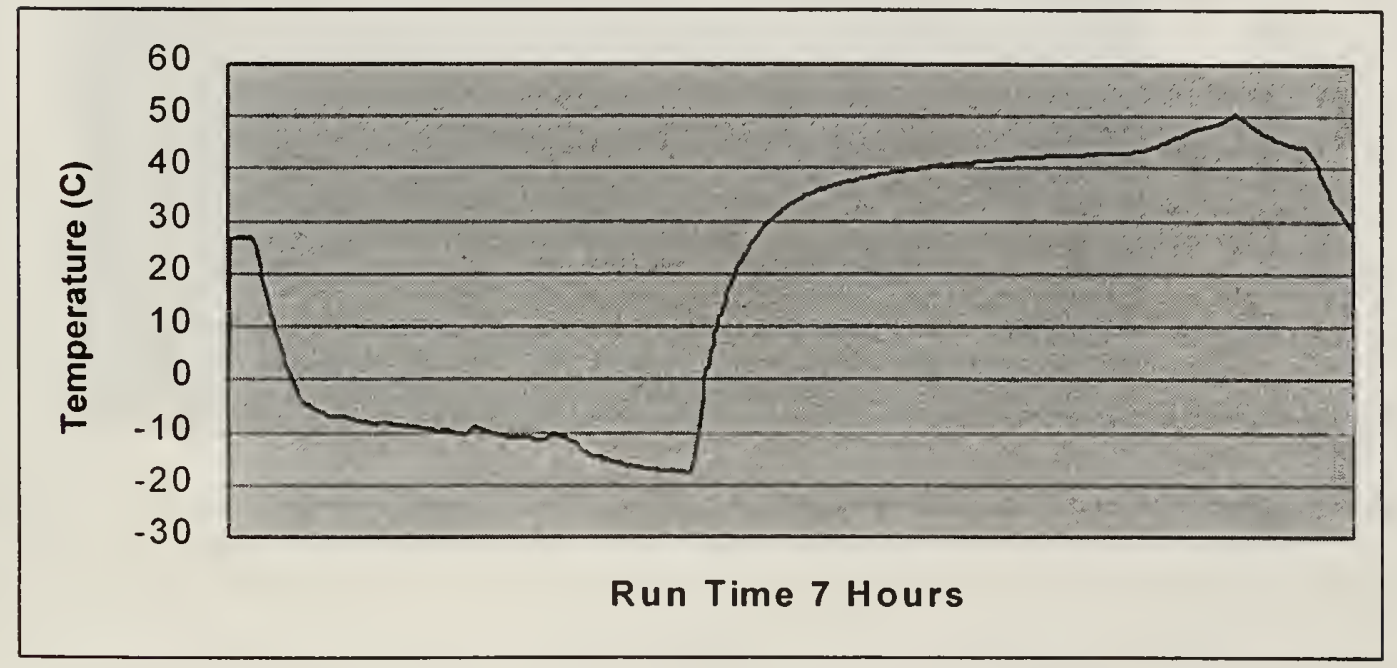

Figure 6.23

TMUX \#2 Thermal Vacuum Run \#2 


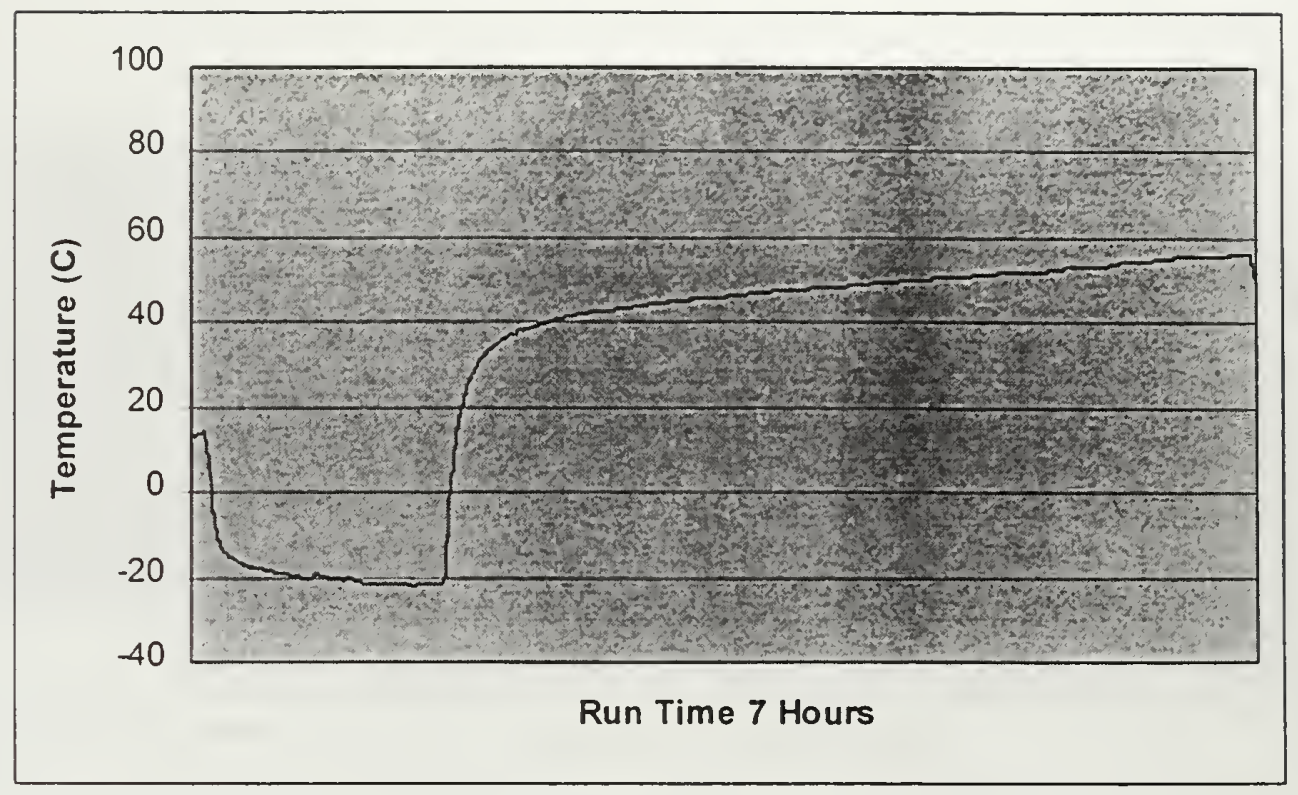

Figure 6.24

EPS \#1 Thermal Vacuum Run \#1

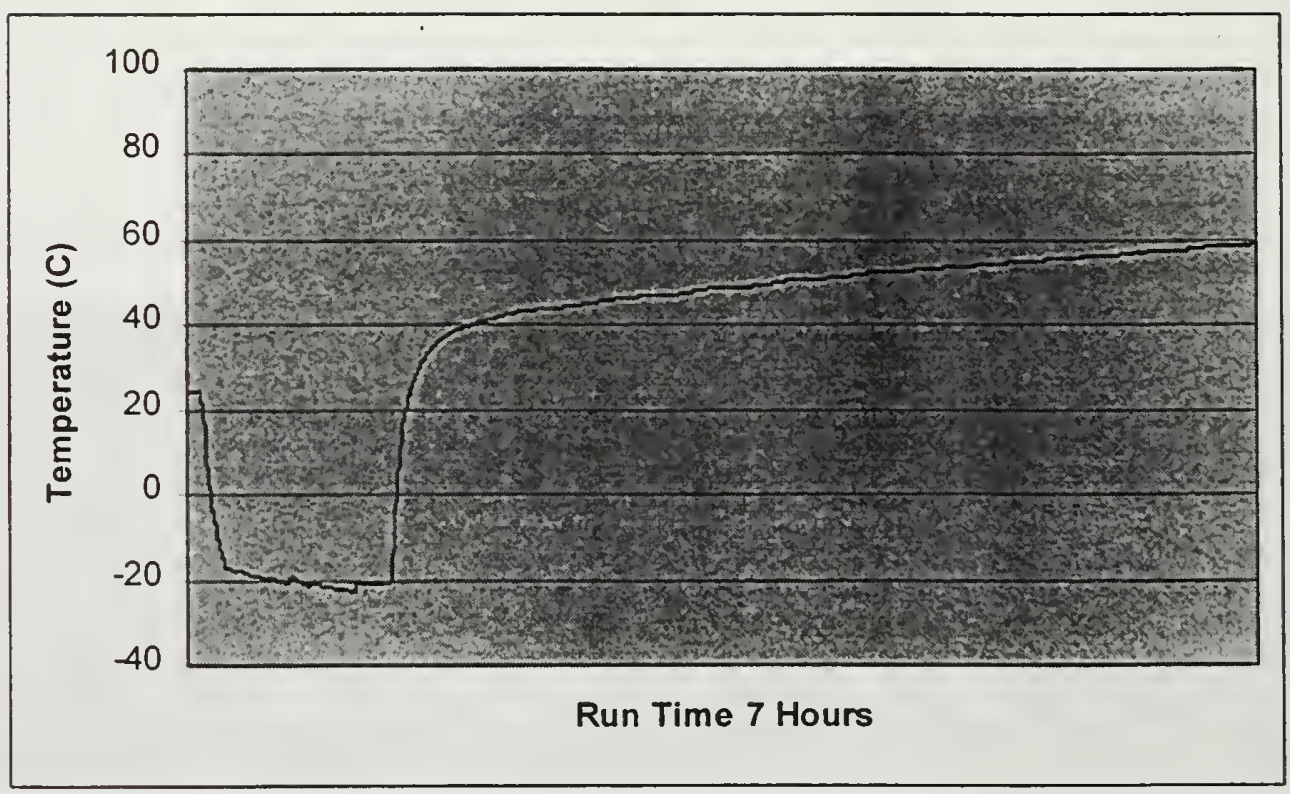

Figure 6.25

EPS \#1 Thermal Vacuum Run \#2 


\section{A. BACKGROUND}

The procedural flow of these tests is designed to best simulate the order in which environmental effects will be experienced in flight. The vibration tests precede the thermal vacuum testing as the launch environment precede on-orbit conditions. Figure A.1 shows the acceptance testing flow for vibration testing.

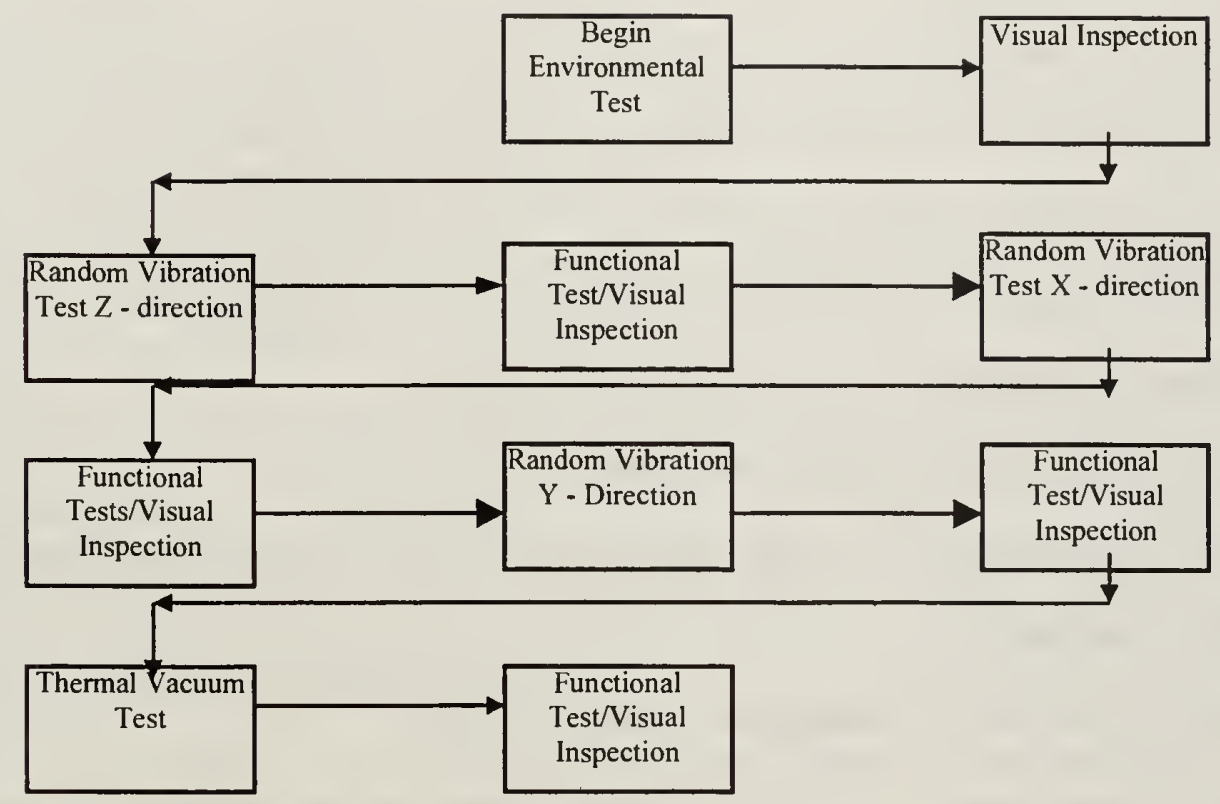

Figure A.l Acceptance Test Flow

The purpose of the visual inspection is to guarantee that each component conforms to the assembly drawings and to identify any physical anomalies that may pose a threat to flight functionality. In addition, the test module should be inspected for broken electrical connections, cracks, scratches and other abnormalities. Functional tests consist of reading and writing software to the modules to ensure that all subsystems are functional and there have been no hardware failures due to the thermal tests or vibration. 


\section{B. RANDOM VIBRATION TEST SCRIPT}

The vibration test setup includes the following test equipment:

MB Dynamics Shaker - PM500A

MB Dynamics Shaker Amplifier - SS2500M

HP 3565S Data Acquisition system with programmable DAC module HP 725/75 Workstation

M\&P International, VCP9000 closed loop vibration control software

Accelerometer calibration is the first step required for the vibration test. The accelerometers are calibrated by standard exciter calibration. The standard exciter used is a Bruel \& Kjaer type 4294 calibration exciter. The B\&K 4294 delivers $10 \mathrm{~m} / \mathrm{s}^{2}$ at $149.2 \mathrm{~Hz}(1000 \mathrm{rad} / \mathrm{sec})$ to a maximum weight accelerometer of 70 grams. The accelerometer is attached to the exciter, activated, and the output is recorded from the signal analyzer. Detailed procedures are as follows:

1. Select three accelerometers. Inspect for any breaks or kinks in the wires

2. Attach an accelerometer to the coaxial cables, via the micro dot connector, and then to the B\&K standard exciter

3. Connect the other end of the coaxial cable to the power supply

4. Connect the power supply to the HP3561A Dynamic Signal Analyzer, via the coaxial cable

5. Start the B\&K 4294

6. The HP 3561 should be set for:

frequency measurements

$400 \mathrm{~Hz}$ bandwidth

$200 \mathrm{~Hz}$ center frequency

$\mathrm{mV}_{\text {rms }}$ vertical scale

averaging selection of at least 10 
7. Record accelerometer data including manufacturer, model number, serial number, and sensitivity

8. Calibrate all three accelerometers

A picture of the MSU undergoing testing is shown in Figure A.2. Hardware setup for the shaker is as follows:

9. Attach the adapter plate to the shaker. Use fasteners of appropriate length to ensure clearance at the bottom of the slip table blind taps. Attach the test article to the adapter plate.

10. Using tack wax attach the accelerometers to the test article and fixture. Attach one of the accelerometers on the fixture; this will be used to form the control signal. Place the other accelerometers on the test article.

11. Tape the accelerometers leads to the fixture with masking tape; leave loose loops to avoid stress concentrations.

12. Connect the accelerometers to the back of the $483 \mathrm{~B} 03$ constant current source, use output $\# 2,3$, and 4 .

13. Connect the cables of 8 channel $3565 \mathrm{~S}$ input 0,1 , and 2 .

14. Turn on the $3565 \mathrm{~S}$ and the $483 \mathrm{~B} 03$.

15. Before turning on the MB Dynamics SS2500M Amplifier, turn the gain knob to "reset", and then press the two "power" buttons simultaneously.

16. Set the gain knob to 10 


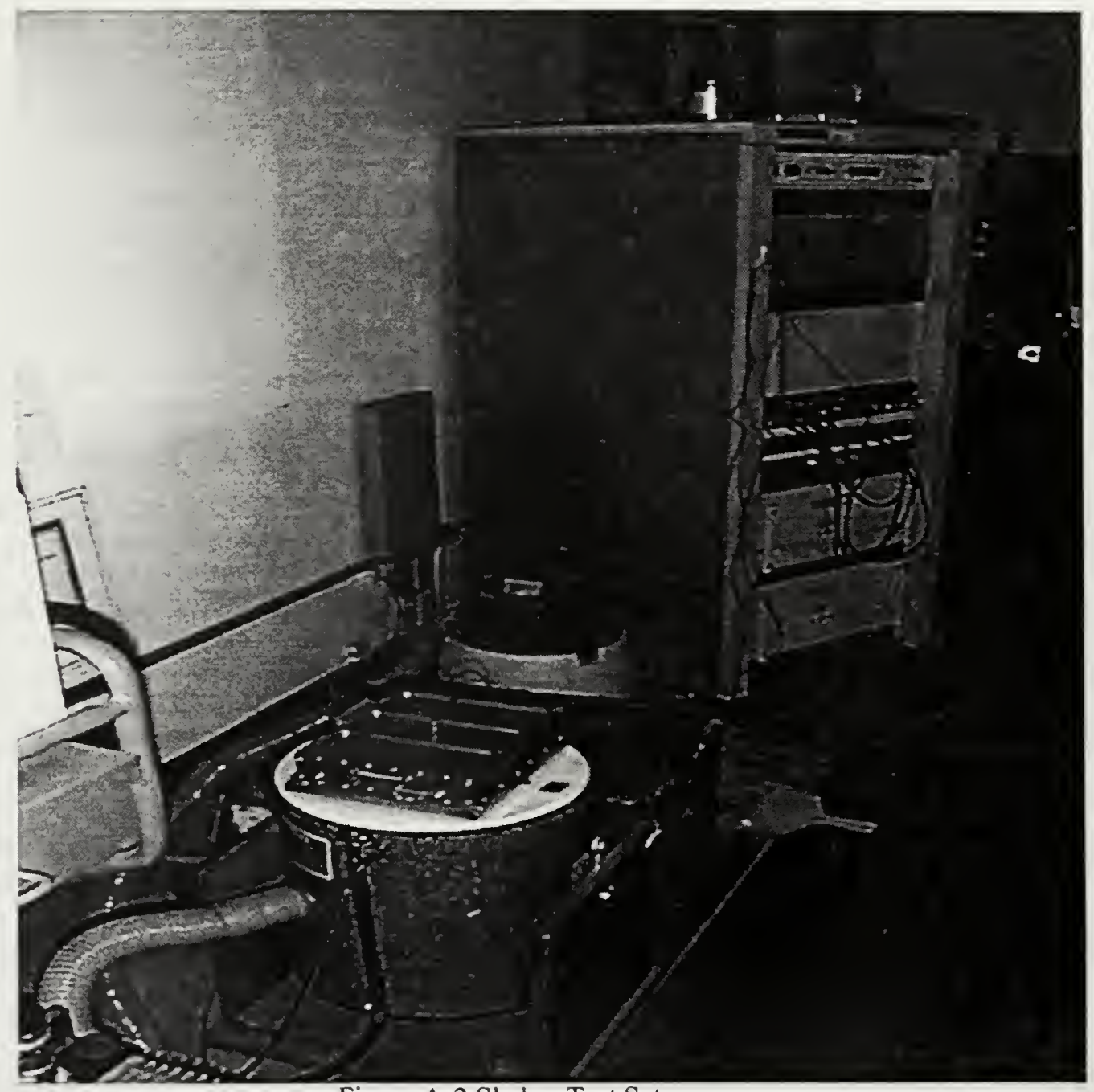

Figure A-2 Shaker Test Setup

Software setup for the random vibration testing is as follows:

1. To start up the closed loop vibration software you must login to the HP $725 / 75$. At the login window select options/no windows. Press return when prompted on the screen. For the console login type vc. The software will ask for a login name; enter vc.

2. A window containing icons will appear on the bottom left of the desktop. Select the shaker icon.

3. Select set-up shaker. Load the MB Dynamics PM500A shaker file through the "files" dialog box. 
4. Select the define icon and choose random spectrum. Load the applicable hitchhiker acceptance spectrum. Check the spectrum to verify that it is correct

5. Select the define icon and choose "specimen info". Insert all relevant test information such as weight of the adapter plate and test article. Insure that the units are consistent.

6. Select "testing schedule". Use the following table for power level sequencing. The duration is required to allow the software to adjust the drive spectrum to create the desired test conditions. If the test is unable to reach the 0 level spectrum without aborting, an increase of duration at lower levels will improve performance.

7. Select the "channel set-up" icon. Enter the sensitivities for the three accelerometers. The accelerometer on the fixture plate is the control channel, and the two accelerometers on the test article are the measurement channels.

8. Select the "run" icon. Load the appropriate test definition, choose the appropriate test method, and give the test a distinguishable name.

9. Run the test. Upon completion of the test, output the data by using the plot utility. Print out the test definition used. 


\section{THERMAL VACUUM TEST}

The thermal vacuum test schedule is shown in Figure A.3

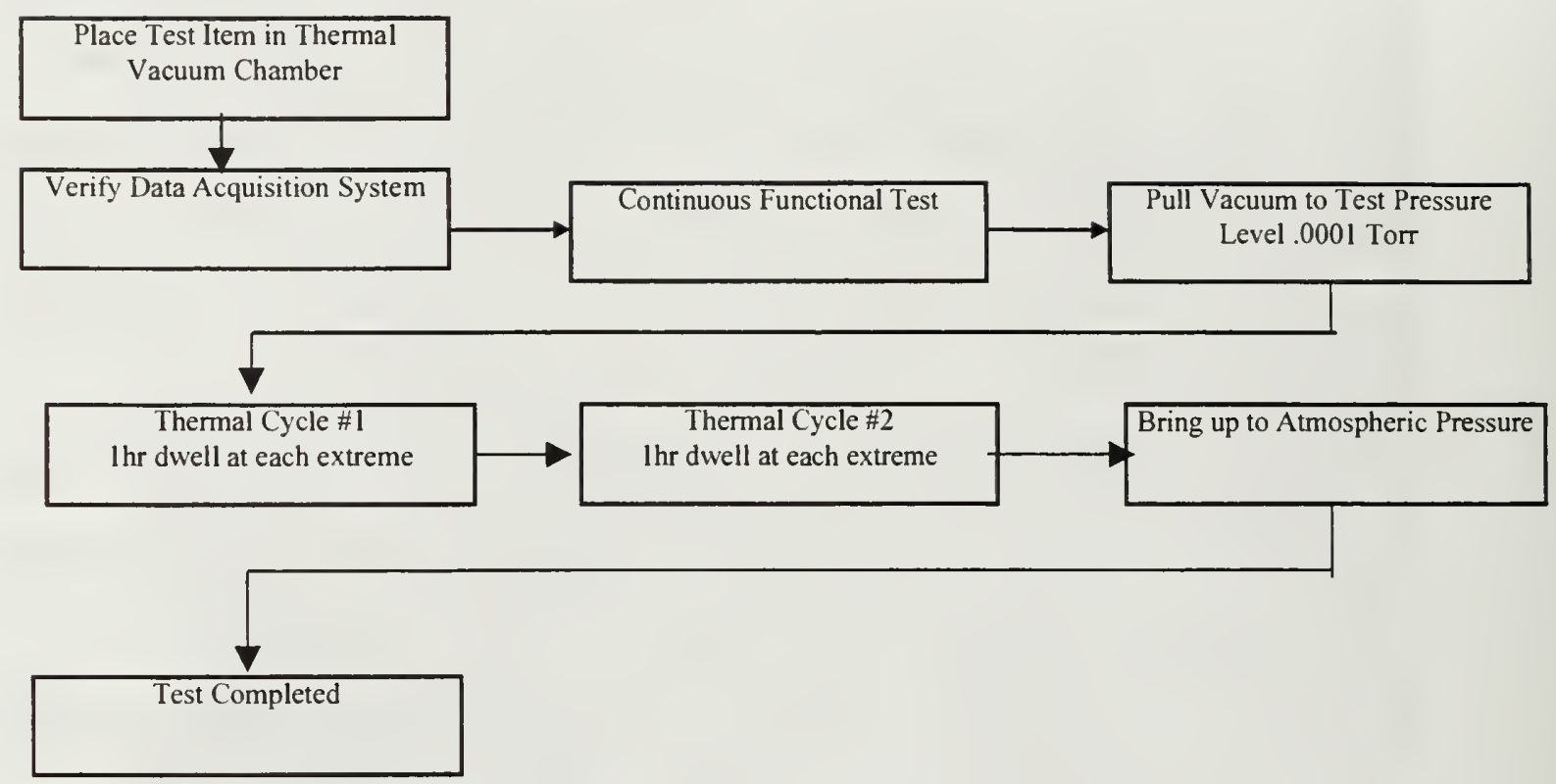

Figure A.3 Thermal Vacuum Cycle Test

Procedures for the thermal vacuum testing are as follows:

Mount or place the device under test into the chamber. Make any electrical connections that need to be made and attach the thermocouples in the desired locations.

1. Turn on the computer and login to the network. Start Windows and open the LabView application. The vi library for the chamber is located on the space systems server with the following path: H:EQUIPT/SPACEJR/tvac.llb. Open this library. Open the vi for reading thermocouple temperatures, reading thermocouples2.subvi. Turn on the SCXI 1000 and power supply located under the chamber

2. Start the reading thermocouples2.subvi at which point you should begin to see temperature data for the different thermocouples.

3. Record in a lab book the corresponding thermocouple channel numbers and locations

4. Stop the reading thermoucouples2.subvi and open the space Jr. Controller.vi.

5. Carefully wipe down the o-ring sealing surface of the door with chem. Wipe and alcohol. 
6. Close the door. Visually inspect the door alignment. Clamp the two over-center clamps with orange handles. Re-inspect

7. Make sure that the valve marked vent on the lower right hand side is closed.

8. Check oil levels in the turbomolecular and mechanical pumps.

9. Check water level in the re-circulator. Check that the valve on the water line on the back of the chamber is open.

10. Put the relay switch on the front of the chamber on "Normal".

11. Record the pump hours run from the front of the turbomolecular pump controller.

12. Start the Space Jr Controller.vi. Enter the necessary information for test documentation. Note that the vi will ask for a temperature set point. This will not be active at the start of the program. Enter $25^{\circ} \mathrm{C}$.

13. Once the controller front panel comes up the temperature alarm limits can be entered and the frequency of data recording can be adjusted.

14. Turn on the Granville Phillips vacuum gauge controller by depressing the switch located on the rear panel. Log the pressure in the chamber and foreline.

15. Energize the main switch on the Tenny space chamber.

16. Check the water level in the re-circulator, put the temperature set point between $10^{\circ} \mathrm{C}$ and $15^{\circ} \mathrm{C}$. Check water lines going from the re-circulator to the turbomolecular pump for any leaks. $\log$ the re-circulator set point.

17. Depress the yellow on/off switch located on the Varian controller; this starts the mechanical pumps.

18. Log the chamber pressure every 5 minutes as the mechanical pumps rough out the chamber. The turbomolecular pump will turn on when the pressure reaches approximately .15 Torr; this should take about 15 minutes.

19. After the chamber pressure reads on the order of $10^{-4}$ turn on the ion gauge.

20. Throughout the remainder of the run, $\log$ the time, pressure and any action that might be done. 
21. Without using the cold trap, bring the chamber down to a pressure on the order of $10^{-5}$ Torr. When this pressure is reached the thermal cycle is ready to begin. 


\section{LIST OF REFERENCES}

1. Severson, Fred J., An Overview of the Petite Amateur Navy Satellite (PANSAT) Project, Master's Thesis, Naval Postgraduate School, Monterey, CA, Dec. 1995.

2. Gannon, Brian B., Design and Analysis of the Launch Vehicle Adapter Fitting for the Petite Amateur Navy Satellite (PANSAT), Master's Thesis, Naval Postgraduate School, Monterey, CA, Sep. 1994.

3. Sakoda, Daniel, Structural Design, Analysis, and Modal Testing of the Petite Amateur Navy Satellite (PANSAT), Master's Thesis, Naval Postgraduate School, Monterey, CA, Sep. 1992.

4. Sakoda, Daniel, "Naval Postgraduate School Spread Spectrum Communication Satellite," AIAA 93-4229, Naval Postgraduate School, Monterey,CA

5. PANSAT Systems Analysis Goup Systems Review, AA4831 Class Project, Spring 1994.

6. Smilowitz, Gary, Final Design, Integration and Validation of the PANSAT Antenna System, Master's Thesis, Naval Postgraduate School, Monterey, CA, Jun. 1997.

7. Horning, J. A., "Navy Education Through Amateur Satellite Development," AIAA 93-4211, Naval Postgraduate School, Monterey, CA.

8. Payne, Robert Andrew Jr., Applications of the Petite Amateur Navy Satellite (PANSAT), Master's Thesis, Naval Postgraduate School, Monterey, CA, Sep. 1992

9. MIL-STD-1546B, Parts, Materials, and Processes Control Program for Space and Launch Vehicles, 15 September 1994

10. MIL-STD-1547B, Electronic Parts, Materials, and Processes for Space and Launch Vehicles, 15 September 1994

11. MIL-STD-1540C, Test Requirements for Launch, Upper-Stage, and Space Vehicles, 15 September 1994.

12. Scott, Allen, An Analysis of Spacecraft Dynamic Testing at the Vehicle Level, Master's Thesis, Naval Postgraduate School, Monterey, CA, Jun. 1996

13. Hershfeld, D.J., "Avoiding Unrealistic Overtest By Notching the Vibration Test Specification," Proceedings of the Institute of Environmental Sciences, 1974.

14. Moening, C.J., "An Overview of Shock, Vibration and Acoustic Environments," The Aerospace Corporation, 1988.

15. Davinic, Nicholas, Evaluation of the Thermal Control System of the Petite Amateur Navy Satellite (PANSAT), Master's Thesis, Naval Postgraduate School, Monterey, CA, Jun. 1995. 


\section{INITIAL DISTRIBUTION LIST}

1. Defense Technical Information Center.................................................. 8725 John J. Kingman Rd., Ste 0944

Ft. Belvoir, VA 22060-6218

2. Dudley Knox Library

Naval Postgraduate School

411 Dyer Rd.

Monterey, CA 93943-5101

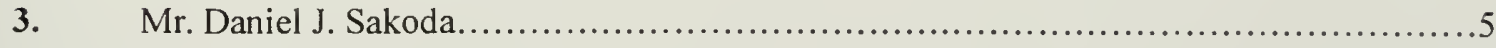

Code SP/SD

Naval Postgraduate School

Monterey, CA 93943-5002

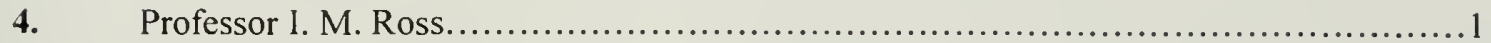

Code AA/Ro

Naval Postgraduate School

Monterey, CA 93943-5002

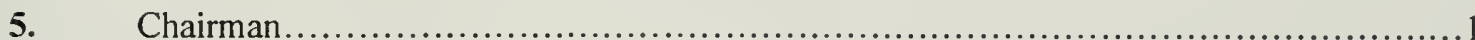

AA Department

Naval Postgraduate School

Monterey, CA 93943-5002

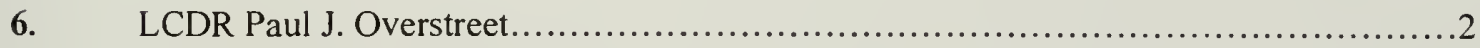

14726 Winterfield CT

Centreville, VA 20120 


$6 \underset{3 H}{4} 2851$

10/99 22527-200 wи 



